\title{
Experimental study on the fire behaviour of reinforced concrete slabs under combined uni-axial in-plane and out-of-plane loads
}

Yong Wang ${ }^{\text {a,b }}$, Guanglin Yuan ${ }^{\text {a }}$, Zhaohui Huang ${ }^{\mathrm{c},}$, Junli Lyv ${ }^{\mathrm{d}}$, Zhi-Qi Li ${ }^{\text {a }}$, Teng-yan Wang ${ }^{\text {a }}$

a State Key Laboratory for Geomechanics \& Deep Underground Engineering, School of Mechanics \& Civil Engineering, China University of Mining \& Technology, Xuzhou, Jiangsu 221116, China

b Jiangsu Collaborative Innovation Center for Building Energy Saving and Construction Technology, Xuzhou, Jiangsu 221116, China

c Department of Mechanical, Aerospace and Civil Engineering, College of Engineering, Design and Physical Sciences, Brunel University, Uxbridge, Middlesex UB8 3PH, UK

d School of Civil Engineering, Shandong Jianzhu University, Jinan, China

\begin{abstract}
In this paper four large scale fire tests on the reinforced concrete slabs, under combined uni-axial in-plane and out-of-plane loading conditions with vertical restraint at four corners of the slabs, are presented. The research focuses on the quantitative relationship between horizontal restrained force and deformations, cracking patterns and spalling of the slabs in fire. Also the vertical restraint forces at the four corners of the slabs were measured in the tests. Comparisons of the results indicate that the compressive uni-axial in-plane loads have a considerable effect on the number and directions of cracks on the top of the concrete slabs in fire. The uni-axial in-plane restrained slabs have larger mid-span deflections and lower deflection recovery ratios than the slabs without in-plane loading. In addition, the test results indicate that increasing reinforcement ratio can effectively prevent the integrity failure of the restrained slabs. The research generates valuable test data which can be used to validate the numerical models developed by fellow researchers in the field of structural fire engineering.
\end{abstract}

Keywords: reinforced concrete slabs; uni-axial in-plane load; out-of-plane load; fire test.

\footnotetext{
b, ${ }^{*}$ Corresponding author.

E-mail address: zhaohui.huang@ brunel.ac.uk (Z. Huang)
} 


\section{Highlights:}

- Conduct four full-scale fire tests on the concrete slabs under combined loads.

- Reveal the complex behaviours of the concrete slabs in fire.

- Investigate the influence of reinforcement ratio on the fire behaviour of slabs.

- Generate valuable test data to validate the numerical models for fellow researchers. 


\section{Introduction}

Previous researches indicate that reinforced concrete floor slabs play a key role in enhancing the fire resistance of composite steel-framed building. In recent years, a number of experimental studies for investigating the fire behaviour of reinforced concrete slabs have been conducted [1-6]. It is acknowledged that the behaviour of reinforced concrete slabs in fire is affected by the slabs' support conditions [6-8].

During the 1960s, the effects of restraint on the fire exposed concrete floor systems were studied at the Portland Cement Association (PCA) [9, 10]. These studies reported that axial restraint of concrete slab increases the fire resistance of floor slabs. However, the tests were carried out mainly for a few types of floor systems, such as precast double tee slabs. In 1982, the analytical studies conducted by Anderberg and Forsen [11] indicated that the fire resistance of flat slabs does not always increase with increasing axial restraint. In 1989, Lin et al. [12] conducted one fire test on a restrained concrete slab with epoxy-coated bars according to the guidelines of ASTM E119. The restraining frames were used to apply in-plane axial forces on the slab during the fire test. It was observed that the applied restraining forces on the test slab resulted in larger deflection. In 1993, Cooke [13] conducted a series of fire tests on restrained concrete flat slabs. The test results show that compressive axial restraint is not always beneficial to the fire resistance of the slabs and the behaviour of the slabs strongly depends on the position of the restraint force applied at the supports. For instance, when the line of thrust at the supports is located at the position closest to the exposed face of the slab, the fire resistance of the slabs is significantly better than the slabs with their line of thrust located at mid-depth of the slab's thickness. The test results also shows that when an axial restraint load applied at mid-depth of the slab at the end supports the fire resistance of the slab is significant reduced compared to the slab without axial restraint. It is clear that there are some obvious controversies on the effect of the restraint on the fire behaviour of concrete slabs from previous fire tests.

In 2002, Lim et al. [3] conducted the fire tests on three reinforced concrete slabs. The slabs with the dimensions of $3.3 \mathrm{~m}$ by $4.3 \mathrm{~m}$ were simply supported on all four edges above the furnace. 
During the tests, the corners of one concrete flat slab were clamped. The test results show that the corner restraint has an important effect on the deformation of concrete slabs. In recent years, a series of small scale reinforced concrete slabs were tested at both ambient and elevated temperatures to investigate the influence of tensile membrane action on the structural behaviour of concrete slabs $[2,14,15]$. However, all slabs were tested under simply supported conditions. In 2009, Wang et al. $[16,17]$ conducted two fire tests on the reinforced concrete slabs in which one slab was simply supported on four edges and another one was fixed on four edges. The experiments indicated that the failure pattern of the slab with four-edge simply supported is significantly different with the four-edge fixed slab. In 2012, Zhu et al. [18] conducted six full-scale fire tests on the two-way reinforced concrete slabs with different support conditions. The test results indicate that the boundary conditions have a considerable effect on the fire behaviour of the slabs, particularly the cracking patterns on the top surface of the slabs.

Previous researches $[4,5,7,19-22]$ have confirmed that the deformations and cracking patterns of the floor slabs within the fire compartments are highly dependent on the locations of the fire compartments within the buildings. The restraints provided by the surrounding structures play a key role in influencing the fire behaviour of the floor slabs. From the literature review presented above it is clear that the majority of the fire tests on reinforced concrete slabs were subjected to simply supported conditions. Hence, further experimental research on the reinforced concrete slabs under fire conditions with well controlled axial restraint forces is needed.

In addition, a review of literature shows that several theoretical models were developed for predicting the ultimate bearing capacity or limit deflections of concrete slabs in fire. Bailey et al. [1-2] developed a theoretical method to determine the capacity of lightly reinforced concrete slabs with large displacements at elevated temperatures. Cameron and Usmani [23] proposed an energy method to calculate the membrane load capacity of a slab based on the failure criterion of steel strain. In addition, based on the fundamental structural mechanics (thermal strain and mechanical strain), Usmani et al. [24] conducted the theoretical analysis of the response of single structural members under a combination of thermal actions and boundary restraints 
(rotationally and laterally). Li et al. [25] presented a new model for analysing the behaviour of floor slabs involving membrane action. In this model, a slab at the limit state was divided into five parts, including four rigid plates and an elliptic paraboloid. Zhang and Li [26] proposed some new assumptions and modifications on the failure pattern and partial parameters of the '5-parameter model' proposed by Li et al. [25] for floor slabs. Dong and Fang [27] proposed a segment equilibrium method to determine the tensile membrane effects of concrete slabs at large displacements. This model considers the tensile membrane action that is provided by the vertical component of reinforcement tensile forces after the formation of the mechanism of the plastic hinge line. According to the model proposed by Dong and Fang [27], Wang et al. [28] presented a modified theoretical model for determining the load carrying capacity of reinforced concrete slabs.

This paper presents for the first time four large scale fire tests on the reinforced concrete slabs which were subjected to combined uni-axial in-plane and out-of-plane loading conditions with vertically restraint at the four corners of the slabs. The research focuses on the quantitative relationship between horizontal restrained force and deformation, cracking pattern and spalling of the slabs in fire. Also the vertical restraint forces at the four corners of the slabs were measured during the tests. The research generated valuable test data which can be used to validate the numerical models developed by fellow researchers in the field of structural fire engineering.

\section{Test programme}

\subsection{Test furnace}

As shown in Fig. 1, a furnace was specially designed and constructed to heat the four concrete slabs based on the original large furnace. The furnace walls were constructed from bricks (370 mm thick) and mineral wool (50 mm thick). The furnace was operated by two oil-fired burner nozzles located in the north furnace wall, and each nozzle was controlled independently. The dimensions of the furnace are $3270 \mathrm{~mm} \times 3270 \mathrm{~mm} \times 1500 \mathrm{~mm}$. 


\subsection{Concrete slabs}

In this research four full-scale reinforced concrete slabs were tested under fire conditions. The slabs were simply supported on four edges and subjected to various combinations of horizontal uni-axial in-plane and vertical out-of-plane loads. It is noted that one slab, named Slab S1, was tested under vertical out-of-plane load only for the purpose of comparison. The other three slabs (named Slab S2, Slab S3 and Slab S4) were tested under combined loading conditions. All four slabs were vertical restrained at four corners. The four slabs were identical in terms of concrete strength, dimensions, and the thickness of concrete cover.

The dimensions of the slabs were $3300 \mathrm{~mm}$ wide by $3300 \mathrm{~mm}$ long with a thickness of $100 \mathrm{~mm}$. All four slabs were cast at the same time then they were stored in the laboratory to cure and dry. The ages of the concrete at the time of testing were: Slab S1=224 days; Slab S2=243 days; Slab S3=253 days; Slab S4=259 days. Commercial normal weight concrete (siliceous aggregates) with the specified cubic compressive strength of $30 \mathrm{MPa}$ was used for the slabs. However, the actual compressive strength of concrete at the time of tests for all slabs was $28 \mathrm{MPa}$.

For the Slabs S1, S2 and S3, grade 3 hot-rolled reinforcing bars of $8 \mathrm{~mm}$ diameter were arranged at $200 \mathrm{~mm}$ spacing along the two directions. For the Slab S4, the space of the reinforcing steel bars for both directions was $100 \mathrm{~mm}$. For each slab, the clear concrete cover was $15 \mathrm{~mm}$ from the steel reinforcing bars. In addition, the reinforcing steel bars were only placed at the bottom of the slabs. The tested yield strength and ultimate strength of the reinforcing steel were 414 and $475 \mathrm{MPa}$, respectively.

\subsection{Instrumentations}

The furnace temperatures were measured by two thermocouples (F-1 and F-2) during each fire test. In addition, for each slab, nine groups of thermocouple trees (T1 to T9) were used to measure the temperatures within the slab, as shown in Fig. 2(a). Each thermocouple tree consisted of 6 thermocouples (see Fig. 2(b) Points T-1 to T-6) distributed vertically to measure 
the concrete temperatures along the thickness of the slab. For measuring the temperatures of reinforcing steel, two thermocouples (Points R-1 and R-2) were placed at the mid-height of the steel bars, as shown in Fig. 2(b).

The vertical and horizontal deflections of each concrete slab were measured in the test. Fig. 3 shows the positions of vertical and horizontal displacement transducers which have limiting travel ranging from 10-500 mm. Eleven LVDT's (Points V1 to V11) were placed on the slab to measure the vertical deflections of the slab and the horizontal deflections of the slab were measured by two LVDT's called H1 and H2, respectively.

\subsection{Test setup and procedure}

The four edges of each slab were supported by steel balls and rollers on four furnace walls, according to the Standards of Concrete Testing Method of China [29]. A uniformly distributed load was applied on the top of each slab, to simulate live loads. Sandbags (each weighing $50 \mathrm{~kg}$ ) were placed on the slab to simulate the uniformly distributed load of $2.0 \mathrm{kN} / \mathrm{m}^{2}$.

As shown in Fig. 4(a), the horizontal uni-axial in-plane loads were applied by one independent loading frame. The uni-axial in-plane loads were applied to the slab by high-strength steel knife edges attached to the rams of the three $500 \mathrm{kN}$ hydraulic jacks along one edge of the slab. At the opposite edge of the slab, three high-strength knife edges were also bolted to the frame to provide the reaction for the applied in-plane loads, as shown in Fig. 4(b). For the Slab S1 the applied in-plane restraint stresses were zero. For the Slabs S2 and S4 the applied uni-axial in-plane restraint stresses were about $2 \mathrm{MPa}$, and thus the force applied by each jack was about $210 \mathrm{kN}$. For the Slab S3 the applied in-plane restraint stresses were about $1 \mathrm{MPa}$, and thus the force applied by each jack was about $105 \mathrm{kN}$.

As shown in Fig. 4(a), during the tests the four corners of each slab were clamped down with four reaction beams placed diagonally across the corners. Each steel beam was bolted to the supporting steel frame. A pressure transducer at each corner was used to measure the vertical restraint force during the fire test. The location of the pressure transducer was at the position $200 \mathrm{~mm}$ away from both edges of the slab (see Fig. 4(a), points P-1 to P-4). 
The four edges of each slab were simply supported by steel balls and rollers on the four reinforced concrete furnace walls. Fig. 4(c) shows the configuration of vertical edge supports. The details of the supports are shown in Fig. 4(d). From the figure it can be seen that there were two steel strips used between the concrete slab and steel balls or rollers, and the furnace walls and steel balls or rollers. Hence, the clear support span of the slabs was $2930 \times 2930 \mathrm{~mm}$.

In the fire test, the Slab S1 was tested under vertical lateral loads only as a reference test. The Slabs S2 to S4 were tested under combined horizontal uni-axial in-plane and vertical out-of-plane loads. For each restrained slab, the vertical lateral loads were firstly applied, and then the horizontal in-plane loads were applied to a predetermined value. The uni-axial in-plane forces were kept constant during the fire test. As indicated in Fig. 4(a), the uni-axial in-plane forces were applied only in the N-S direction and were measured by three pressure transducers (Points P-5, P-6 and P-7).

As indicated in Fig. 4(b), the horizontal uni-axial in-plane loading units were supported by the original furnace walls, and thus the vertical deflection of the slab would not develop a vertical reaction in the horizontal loading system. In other words, as the edges of the slab deformed up or down, the horizontal uni-axial in-plane loading frame also moved up or down.

\section{Test results and discussions}

This section discusses the experimental results for each test along with a detailed explanation for the observed behaviour. The main results include the temperature, deflections and restrained forces during the heating and cooling phases. Observations on the cracking pattern and concrete spalling of the four slabs are also presented. Additionally, the test results are compared with each other and those reported in the literature to more fully understand the effect of the restraint and steel reinforcement ratio on the fire behaviour of concrete slabs.

\subsection{Thermal response}

\subsubsection{Furnace temperature}


The measured furnace temperatures against time during both the heating and cooling phases for the four tests are shown in Figs. 5(a)-5(d). The furnace was shut off at 180 min after ignition in each test. It is noted that the data at Point F-2 in the Slab S4 test were not recorded due to the hardware problems. It is clear that, for the Slabs S1 to S3, the furnace temperatures measured by the two thermocouples F-1 and F-2 were similar. During the heating stage, the maximum furnace temperatures for the Slabs $\mathrm{S} 1$ to $\mathrm{S} 4$ were $906{ }^{\circ} \mathrm{C}, 913{ }^{\circ} \mathrm{C}, 930{ }^{\circ} \mathrm{C}$ and $853{ }^{\circ} \mathrm{C}$, respectively. In addition, the average furnace temperatures of the four slabs at the test time of 180 min were $827{ }^{\circ} \mathrm{C}, 800{ }^{\circ} \mathrm{C}, 918{ }^{\circ} \mathrm{C}$ and $837{ }^{\circ} \mathrm{C}$, respectively. It can be seen that the furnace temperatures of the four tests were well below the ISO Fire curve. However, the four slabs had similar average furnace temperature-time curves, indicating that the fire behaviour of the four slabs can be compared with each other. After $180 \mathrm{~min}$, the furnace temperature decreased rapidly, and three tests (Slabs S1, S2 and S4) finished at $400 \mathrm{~min}$ after furnace ignition. Due to the malfunction of the collecting instrument, the fire test of the Slab S3 finished at 275 min. Tables 1 and 2 show the average furnace temperature-time history for each test during the heating and cooling stages.

From the Figs. 5(a)-5(d) it can be seen that during the initial stage of each test, the furnace temperature-time curve followed the specified ISO834 fire curve very closely. As the tests continued, the furnace temperatures showed significant deviation from the temperatures of the ISO standard fire, particularly in Slabs S2. This was due to insufficient air ventilation into the furnace and water escaped from the slab which caused incomplete combustion and resulted in a lot of black smoke pouring out of the furnace. However, this difference does not affect the comparison of the present tests and other results which were generated by similar furnace temperature-time trends $[3-6,17]$.

\subsubsection{Temperature of the concrete slabs}

\section{(1) Concrete temperatures}

Figs. 6(a)-6(d) show the temperature profiles along the cross sections of the Slabs S1 to S4. It can be found that the temperature gradients in the four slabs increased quickly with time. For instance, at $180 \mathrm{~min}$, the temperatures on the bottom surface of the four slabs reached to $626^{\circ} \mathrm{C}$ (S1-T4-1), $697{ }^{\circ} \mathrm{C}(\mathrm{S} 2-\mathrm{T} 1-1), 811^{\circ} \mathrm{C}$ (S3-T3-1) and $722{ }^{\circ} \mathrm{C}$ (S4-T9-1), respectively. Meanwhile, at $180 \mathrm{~min}$, the corresponding temperatures on the top surfaces of the slabs were $92^{\circ} \mathrm{C}$ (S1-T4-6), $78{ }^{\circ} \mathrm{C}(\mathrm{S} 2-\mathrm{T} 1-6), 230{ }^{\circ} \mathrm{C}(\mathrm{S} 3-\mathrm{T} 3-6)$ and $163{ }^{\circ} \mathrm{C}(\mathrm{S} 4-\mathrm{T} 9-6)$, respectively. 
It is evident that due to the lower thermal conductivity of concrete, the temperature distribution along the thickness of the heated slab was very nonlinear. The temperature of the slab's surface exposed to fire was much higher compared to the unexposed surfaces of the slabs. The temperature differences between the bottom and top surfaces of Slabs S1 to S4 were $534{ }^{\circ} \mathrm{C}$, $619{ }^{\circ} \mathrm{C}, 581{ }^{\circ} \mathrm{C}$ and $559{ }^{\circ} \mathrm{C}$, respectively. No doubt, the high temperature difference caused the exposed surface (bottom surface) to expand much more than the unexposed surface (top surface). This is main driving force to generate the thermal bowing of the slabs under fire conditions. As discussed in Refs. [23-24] the thermal bowing is one of the main driving forces to generate vertical deflection of the slabs in fire, particularly at the early stage of a fire test.

Similar to the results observed in Refs. [3, 17], there are short temperature plateaus and the temperature hysteresis near to the unheated regions of each slab.

\section{(2) Rebar Temperature}

Figs. 7(a)-7(d) illustrate the temperature developments of the reinforcing bars for the Slabs S1 to S4. As expected, for each test, the measured temperatures at different points are very similar during the initial stage. As the tests continued, the temperature differences between different positions slowly increased, particularly at $180 \mathrm{~min}$. This may be attributed to the water evaporation and concrete spalling. For example, as shown in Fig. 7(a), at $180 \mathrm{~min}$, the maximum and minimum temperatures in the bottom reinforcing bars of the Slab $\mathrm{S} 1$ were $584{ }^{\circ} \mathrm{C}$ (T4-R-1) and $498{ }^{\circ} \mathrm{C}$ (T6-R-2), respectively. The similar conclusions can be obtained from the Slabs S2, S3 and S4, as shown in Figs. 7(b)-7(d).

However, it is interesting to note that the average steel temperatures of the four slabs were similar during the heating stage. These results further indicate that the fire behaviour of the four slabs can be compared with each other due to the similar steel temperatures. It can be seen that for the four slabs, the average temperature of the reinforcing steels did not exceed $593{ }^{\circ} \mathrm{C}$. Hence, the four slabs had good fire-resistance performance according to the conventional strength failure criteria [30].

In addition, there are short temperature plateaus on the bottom reinforcing bars of the Slabs S1 and S2. The durations of the plateau for the Slabs S1 and S2 were about 50 min (100-150 min) and $70 \mathrm{~min}(110-180 \mathrm{~min})$, respectively. Clearly, this is mainly attributed to the decrease in furnace temperature, as shown in Figs. 6(a) and 6(b). As discussed later, this will have an important effect on the fire behaviour of the two slabs, particularly the vertical and horizontal deflections of the two slabs. 


\subsection{Deflection response}

This section discusses the vertical (out-of-plane) and horizontal (in-plane) deflections of the four concrete slabs during the heating and cooling phases. For the vertical deflections, negative displacement is downward and positive displacement is upward, while for the horizontal deflections, positive displacement indicates inward movement (contraction), and negative displacement indicates outward movement (expansion).

\subsubsection{Vertical deflections}

(1) Deflection-time curves

The measured vertical deflections during both the heating and cooling phases for the Slabs S1 to S4 are presented in Figs. 8(a)-8(d). Clearly, there are similar overall mid-span deflection trends for the three restrained slabs. However, the maximum deflection of the Slab S1 (without restraint forces) is significantly less than the restrained slabs. This behaviour is similar to the observations by Cooke [13] who reported that a restrained flat slab with line of thrust acting at the mid-depth of the slab showed worse fire behaviour compared to an unrestrained slab.

From the figures it can be seen that the uni-axial in-plane restrained force has little effect on the initial deflections or the deflection rates of the slabs. For instance, at $60 \mathrm{~min}$, the mid-span deflections of the Slabs S1 to S4 were $54 \mathrm{~mm}, 54 \mathrm{~mm}, 63 \mathrm{~mm}$ and $61 \mathrm{~mm}$, respectively. The corresponding deflection rates during the first $60 \mathrm{~min}$ were $0.9 \mathrm{~mm} / \mathrm{min}, 0.9 \mathrm{~mm} / \mathrm{min}$, $1.0 \mathrm{~mm} / \mathrm{min}$ and $1.0 \mathrm{~mm} / \mathrm{min}$, respectively. During the initial stage of the fire tests, the vertical deflections of the four slabs were mainly due to the thermal bowing resulted from the non-linear temperature gradient along the thickness of the slabs, as discussed in Refs [23-24] (see Figs. 6(a)-6(d)). At this stage the temperatures of concrete and steel reinforcement were relatively low (below $350{ }^{\circ} \mathrm{C}$ ). Hence, the stiffness of each slab was similar. In addition, varying the area of the reinforcement had no obvious effect on the deflection behaviour of the slabs during this stage. Also it is evident that the compressive uni-axial in-plane restraint force has little influence on the deflections of the slabs during this stage. This is mainly due to the restraint forces being applied at the mid-depth of the slabs and the P- $\Delta$ effect was smaller. However, as disused in Refs. [8, 23-24], the axial restraint is effective if the position of the line of thrust is located below the centroidal axis (mid-depth). If the thrust of restraint force acting below the centroidal axis a hogging moment can be generated. Thus, the maximum sagging moment at the mid-span of the slabs will be reduced. Hence, the deflections of the slabs are reduced as well. In this case 
the uni-axial in-plane restraint force is beneficial to the slab fire resistance performance only if the deflections are small. If the deflections exceed the distance of line of thrust to the centroid at the supports, the flexural enhancement due to the external thrust is lost. Instead, the applied restraint forces become detrimental to the slabs due to $P-\Delta$ effect. As discussed above, during the four fire tests, the uni-axial in-plane restraint force was at the location on the centroidal axis at the supports of the slabs, hence, the flexural enhancement (hogging moment) at the mid-span was lost. The effect of the increasing uni-axial in-plane restraint forces was also small due to the lower deflection and higher stiffness during the initial stage of the fire tests. This observation also was reported in Ref. [31] that the restraint slab with low uni-axial restraint force behaved similarly to no restraint slab during the initial stages of the fire tests. Therefore it can be concluded that the thermal bowing of the slabs is a dominant factor to govern the deflection behaviour of the slabs at initial stage of the fire tests.

However, as the tests continued, the effect of the uni-axial in-plane restraint forces on the deflections of the restrained slabs becomes evident, particularly at the later stages. As shown in Fig. 8(a), there is a plateau of mid-span deflection of the Slab S1 between 85 min and 120 min. This is attributed to the temperature plateau of the bottom reinforcing steel (see Fig. 7(a)). However, it is noted that there is a temperature plateau for the bottom steel of the Slab S2 due to the decreased furnace temperature (see Fig. 7(b)). In contrast to the Slab S1, the mid-span deflection of the Slab S2 always increased until the fire test was stopped at $180 \mathrm{~min}$. Between 60 to 180 min test time, the mid-span deflections of the three restrained slabs are considerably greater than the slab without restraint (Slab S1). For instance, at $180 \mathrm{~min}$, the mid-span deflections of the Slabs S1 to S4 were $76 \mathrm{~mm}, 120 \mathrm{~mm}, 100 \mathrm{~mm}$ and $101 \mathrm{~mm}$, respectively. Compared with the mid-span deflection of the Slab S1, the mid-span deflections of the Slabs S2, S3 and S4 were increased by $56 \%, 33 \%$ and $38 \%$, respectively. This is due to the $P-\triangle$ effect generated from the uni-axial in-plane restraint forces.

The test results indicated that during the later stage of the fire tests, the temperatures of concrete and reinforcement increased significantly (see Figs. 6(a)-6(d)), hence, the material properties of concrete and reinforcing steel were decreased considerably with the increasing temperatures. This produced the lower structural stiffness and higher deflections of the tested slabs. Meanwhile, this is also due to the $P-\triangle$ effect generated from the uni-axial in-plane restraint forces. Since the position of line of thrust at the supports was located in the centroidal axis (mid-depth), the applied compressive forces did not enhance the flexural resistance. In contrast, 
the restraint force produced an additional sagging moment at larger deflections, which accelerated the development of the sagging moments at mid-span of the tested slabs, as indicated in Ref. [32]. According to the above mechanical analysis, it can be concluded that the material degradation and $P-\Delta$ effect resulting from in-plane restraint forces are two main factors governing the structural response of the slabs in later stage of a fire.

The above comparisons indicate that apart from the furnace temperatures, the uni-axial in-plane restraint forces applied on the concrete slabs also play a vital role which dominates their structural behaviour at later stage of the fire tests. Hence, it can be concluded that the uni-axial in-plane compressive forces become detrimental to the fire-resistant performance of the slabs during the later stages. The conclusion further confirms the observations by Cooke [13] who reported that restrained flat slabs showed worse fire resistance than simply supported slabs.

In addition, the corresponding mid-span deflection ratios of the Slabs S1 to S4 at 180 min were $0.28 \mathrm{~mm} / \mathrm{min}, 0.64 \mathrm{~mm} / \mathrm{min}, 0.40 \mathrm{~mm} / \mathrm{min}$ and $0.32 \mathrm{~mm} / \mathrm{min}$, respectively. According to BS 476 [33], the failure of a slab is assumed to occur as the deflection or rate of deflection exceeds the limit value of $l / 30$ or $l^{2} /(9000 \mathrm{~d})$. Clearly, the mid-span deflections of the four slabs did not reach the two deflection limit states. These results indicate that based on the above failure criteria, the four slabs have more than $180 \mathrm{~min}$ fire resistance. However, as discussed later, the integrity of the restrained concrete slabs cannot be guaranteed with the large deflections.

As reported in Ref. [23], in the fire scenario, defining failure using artificial deflection limits such as $(\operatorname{span} / 30$ or span/20) is not appropriate due to the thermal expansion and thermal bowing of slabs. Hence, a more scientific and reasonable approach is to apply a limiting value of the mechanical strain of reinforcing steel bars based on the ductility of steel [23-28]. It is assumed that the ultimate bearing capacity of the slabs has been reached when the mechanical strain limit (such as $1.5 \%$ and $2.5 \%$ ) is reached in the reinforcing bars. However, the present test results indicate that the integrity failure of the restraint slab may occur when the deflections are well below the deflection limit (span/30 or span/20). Hence, the integrity failure needs to be considered in the future theoretical models of the restrained slabs under fire conditions.

During the cooling stage, it is noted that the vertical deflections of the Slab S3 are not presented after $275 \mathrm{~min}$ because the instruments of data collecting malfunctioned. As shown in Figs. 8(a)-8(d), it is clear that the restrained and unrestrained concrete slabs have different deflection recovery trends during this stage. For the Slab S1, there was a nonlinear deflection 
recovery trend and the residual mid-span deflection was about $50 \mathrm{~mm}$ at $400 \mathrm{~min}$, and the recovery value was about 35\%. However, the mid-span deflections of restrained Slabs S2 and S4 were recovered almost linearly over the time during the cooling phase. The residual mid-span deflections of the Slabs S2 and S4 were about $110 \mathrm{~mm}$ and $79 \mathrm{~mm}$ at $400 \mathrm{~min}$, respectively and the recovery values of the Slabs S2 and S4 are 7.5\% and 22\%, respectively.

Clearly, these lower recovery ratios of the restrained slabs, particularly the Slab S2, are mainly due to the in-plane forces and the larger cracks on the top surfaces. In fact, in a full-scale fire test on a composite steel-framed building the concrete floor had a similar linear deflection recovery trend, as reported in Refs. $[4,5]$. Based on the test results it can be concluded that the uni-axial in-plane restraint forces have a significant effect on the deflection behaviour of the concrete slabs during the cooling phase of the fires.

(2) Deflection-average furnace temperature curves

Figs. 9(a)-9(d) show the vertical deflections versus average furnace temperature curves for the Slabs S1 to S4. It can be seen from the curves that there are two deflection stages for each slab during the heating phase. When the furnace temperature was less than $600^{\circ} \mathrm{C}$ the central deflections of the slabs were relatively small. However, after the furnace temperature was greater than $600^{\circ} \mathrm{C}$ the slabs deflected rapidly until the furnace was shut-off. As mentioned earlier, the steel reinforcement of the Slabs S1, S2 and S3 were $251 \mathrm{~mm}^{2} / \mathrm{m}$ in each direction, but the Slab S4 had steel reinforcement of $502 \mathrm{~mm}^{2} / \mathrm{m}$ in each direction. It can be seen that the deflection-furnace temperature curves of the concrete slabs are sensitive to the reinforcement ratio. The higher reinforcement ratio tends to cause the higher recovery rate of the slab's deflection during the cooling stage.

\subsubsection{Horizontal deflections}

Figs. 10(a)-10(d) show the measured horizontal deflections (Point H1) of the four concrete slabs. The horizontal deflections were due to the expansion of the concrete slabs. The horizontal deflection trends of the slabs are similar to the vertical deflections of the slabs during the heating and cooling stages.

As shown in Fig. 10, the Slab S1 expanded at a nonlinear ratio until $100 \mathrm{~min}$ and followed by a plateau between 100 and $150 \mathrm{~min}$. The maximum outwards deflection reached $15.2 \mathrm{~mm}$ at $180 \mathrm{~min}$. The horizontal deflection of the Slab S2 started with a non-linear expansion during the initial heating stage, followed by fluctuation between 100 and $120 \mathrm{~min}$. After $120 \mathrm{~min}$, the slab 
expanded again at a liner rate until $19.4 \mathrm{~mm}$ was reached at $180 \mathrm{~min}$. Clearly, due to the effect of the in-plane force, the horizontal deflection of the Slab S2 was always larger than the Slab S1 during the heating stage. It is interesting to note that the maximum horizontal deflections of the Slabs S3 and S4 were 24.1 and $26.4 \mathrm{~mm}$ at $180 \mathrm{~min}$, regardless of the Slab S4 with larger in-plane forces. This may be due to more reinforcement used for the Slab S4.

During the cooling stage, the Slab S1 contracted nonlinearly but each restrained slab contracted linearly. At $400 \mathrm{~min}$, the residual horizontal deflections of the Slabs S1, S2 and S4 were $8.1 \mathrm{~mm}, 20.2 \mathrm{~mm}$ and $19.5 \mathrm{~mm}$, respectively. Hence, it can be concluded that the restrained slabs have lower deflection recovery performance due to the presence of the restraint forces. It is clear that the uni-axial in-plane restraint force has a significant effect on the horizontal deflections of the slabs during the heating and cooling phase.

\subsection{Restraint forces}

In this section, the restraint forces for the four slabs are briefly discussed, including the uni-axial in-plane compressive forces applied by the jacks and the reaction forces at the corners of the slabs. In the Figs. (11) and (12), the positive forces represent compressive forces acting on the slabs.

\subsubsection{Uni-axial in-plane forces}

\section{(1) Slab S2}

During the test, the applied uni-axial in-plane stress for the Slab S2 was about $2 \mathrm{MPa}$, and thus the force applied by each jack was about $210 \mathrm{kN}$. Due to the string attached to the pressure sensors being burnt during the test, the uni-axial in-plane forces applied by three hydraulic jacks were not measured by pressure sensors P-5 to P-7. However, from the pressure gauges installed in the jack, the force applied by each jack kept about $210 \mathrm{kN}$ during the test.

\section{(2) Slab S3}

During the test, the uni-axial in-plane stresses of the Slab S3 were about $1 \mathrm{MPa}$, and thus the force applied by each jack was about $105 \mathrm{kN}$. Fig. 11(a) shows the uni-axial in-plane forces measured from the pressure sensors P-5 to P-7 in the fire test. As the fire started, the applied force in Point P-5 increased rapidly, reaching about $162 \mathrm{kN}$ at $75 \mathrm{~min}$. After that, the jack started to fail, shown by the sudden decrease of force. The reason is that the jack was heated by the hot flames. At this point, the other two jacks were protected as quickly as possible by wet mineral 
wool. After the jack (Point P-5) suddenly failed, the force at Point P-7 also increased very rapidly, reached to about $126 \mathrm{kN}$ at $90 \mathrm{~min}$. And then, this force kept constant between 100 and 130 min. In addition, for Point P-6, the force slightly increased between 75 and 150 min, reaching to about $117 \mathrm{kN}$ at $150 \mathrm{~min}$. Subsequently, the forces at Points P-6 and P-7 kept constant until the end of the fire test. At $275 \mathrm{~min}$, the in-plane forces at Points P-6 and P-7 were $82 \mathrm{kN}$ and $103 \mathrm{kN}$, respectively. The test results indicate that the protected methods used in the fire test were effective and reasonable.

\section{(3) Slab S4}

During the test, the uni-axial in-plane stresses of the Slab S4 were about $2 \mathrm{MPa}$, and thus the force applied by each jack was about $210 \mathrm{kN}$. Fig. 11(b) shows the uni-axial in-plane forces measured from the pressure sensors P-5 to P-7 in the fire test. Clearly, unlike the previous tests, the jacks and the pressure sensors functioned well and recorded data during heating and cooling stages. For instance, during the heating stage, the average values of Points P-5 to P-7 were $184 \mathrm{kN}, 194 \mathrm{kN}$ and $203 \mathrm{kN}$, respectively, and those during the cooling stage were $211 \mathrm{kN}$, $217 \mathrm{kN}$ and $193 \mathrm{kN}$, respectively. The good test results imply that the instruments were effectively protected by wet mineral wool during the test.

\subsubsection{Corner restraint forces}

The variations of the restrained forces at the four corners of the slabs were measured during the four fire tests. The main observed results are presented in the following:

\section{(1) Slab S1}

Fig. 12(a) shows the reaction forces measured by the pressure sensors (Points P-1 to P-4) at the four corners of the slab. It is apparent that the reaction forces fluctuated considerably and showed different trends during the heating and cooling stages. During the initial stage, the force at each corner rapidly increased. Before $15 \mathrm{~min}$, the maximum values of reaction forces at Points P-1 to P-4 were $6.7 \mathrm{kN}, 5.3 \mathrm{kN}, 9.9 \mathrm{kN}$ and $5.0 \mathrm{kN}$, respectively. After that, the reaction forces at the four corners showed different trends, indicating that the force redistribution of the slab occurred during this stage. This is due to the fact that the diagonal cracks gradually occurred at the corners of the slabs, as discussed later. After about $45 \mathrm{~min}$, the reaction forces at Points P-1 and P-3 started to decrease until the furnace was shut-off. However, at Points P-2 and P-4, the reaction forces kept constant between 45 and $100 \mathrm{~min}$, with the average forces of $5.3 \mathrm{kN}$ and $5.8 \mathrm{kN}$, respectively. After $100 \mathrm{~min}$, the reaction force at Point P-2 gradually 
decreased, but at Point P-4 the reaction force slowly increased until $180 \mathrm{~min}$. Finally, at $180 \mathrm{~min}$, the reaction forces at Points P-1 to P-4 were $1.5 \mathrm{kN}, 2.9 \mathrm{kN}, 2.4 \mathrm{kN}$ and $6.0 \mathrm{kN}$, respectively. Clearly, compared with those of the three points, the reaction force at Point P-4 was larger due to the high stiffness (less cracks). This indicates that the number and location of diagonal cracks within the slab has an important effect on the reaction forces at the corners of the slab.

During the cooling stage, the reaction forces at Points P-2 to P-4 gradually decreased. In contrast, the force at Point 1 gradually increased due to the force equilibrium of the slab. At about $200 \mathrm{~min}$, the reaction forces at four points were $5.6 \mathrm{kN}, 0 \mathrm{kN}, 0.1 \mathrm{kN}$ and $4.1 \mathrm{kN}$, respectively. After that, the forces were not recorded due to the electric problem with the data logger.

(2) Slab S2

Fig. 12(b) shows the reaction forces measured by pressure sensors at Points P-1 and P-3, and the data at Points 2 and 4 in the test were not recorded due to hardware problems. Similar to the Slab S1, the reaction forces at Points P-1 and P-3 rapidly increased during the initial stage of the fire, and the maximum value of two points were about $11.2 \mathrm{kN}$ and $5 \mathrm{kN}$, respectively. After about $25 \mathrm{~min}$, the reaction forces of two points gradually decreased due to the diagonal cracks occurring within the slab. After about $120 \mathrm{~min}$, the reaction force at Point P-1 gradually increased to $5.2 \mathrm{kN}$ at $180 \mathrm{~min}$. In contrast, the reaction force at Point P-3 slightly fluctuated and then gradually decreased to $2.3 \mathrm{kN}$ at $180 \mathrm{~min}$. Clearly, the reaction force at Point P-3 was always lower than the Point P-1 during the heating stage.

During the cooling stage, the reaction force at Point P-3 gradually increased and reached to $8.8 \mathrm{kN}$ at $400 \mathrm{~min}$. However, the reaction force at Point P-1 slowly decreased and reached to $2.5 \mathrm{kN}$ at $400 \mathrm{~min}$. After $250 \mathrm{~min}$, the reaction force at Point P-1 was larger than Point P-3. This is different from the behaviour during the heating stage.

\section{(3) Slab S3}

Fig. 12(c) shows the restraint forces at the four corners of the slab in fire. During the heating stage, the restraint forces at the four corners fluctuated significantly, particularly at Points P-1 and P-3. At Points P-2 and P-4, the reaction forces gradually increased as the test continued. The results indicate that the trend of reaction force at each corner is very complex and highly 
dependent on the structural stiffness of the slab. During the heating stage, the maximum forces at the four points were about $8.3 \mathrm{kN}, 6.4 \mathrm{kN}, 5.0 \mathrm{kN}$ and $5.0 \mathrm{kN}$, respectively.

In contrast, during the cooling stage, the forces at Points P-1 and P-4 gradually decreased until the end of fire test, reached $3.0 \mathrm{kN}$ and $2.0 \mathrm{kN}$ at $400 \mathrm{~min}$, respectively. Clearly, the forces at the two points were smaller than those during the heating stage. However, the forces at the other two corners (Points P-2 and P-3) rapidly increased, reaching $13.0 \mathrm{kN}$ and $9.0 \mathrm{kN}$ at $400 \mathrm{~min}$, respectively. Hence, similar to the previous tests, the restraint forces have different trend at various corners due to the different structural stiffness of the slab. This result shows that the force distribution of the restrained slab was very complex during the cooling stage.

\section{(4) Slab S4}

The reaction forces at the four corners of the Slab S4 are plotted against time, as shown in Fig. 12(d). It is noted that the reaction force at Point P-2 sharply increased, with the value of about $17 \mathrm{kN}$ at $30 \mathrm{~min}$. Subsequently, the corner of the slab suddenly failed due to the concrete crushing. After that, the restraint force was not measured at Point P-2 since the pressure sensor was found to be malfunctioning. However, this corner was also clamped by the reaction beam during the entire test. Unlike the reaction force of Point P-4, the reaction forces at Points P-1 and P-3 gradually increased as the test continued. At $180 \mathrm{~min}$, the reaction forces of the two points were about $5.3 \mathrm{kN}$ and $5.4 \mathrm{kN}$, respectively. For Point P-4, between 30 and $180 \mathrm{~min}$, the restraint force slightly increased and then maintained at steady state (about $1.1 \mathrm{kN}$ ).

During the cooling stage, the reaction forces at Points P-1, P-3 and P-4 show different trends between 180 and $250 \mathrm{~min}$. After that, the reaction forces at the three points kept constant, with the average values of $6.3 \mathrm{kN}, 6.5 \mathrm{kN}$ and $5.3 \mathrm{kN}$, respectively. Clearly, different from those observed in the previous tests, the restraint forces at the three points were similar to each other during this stage. In fact, the phenomenon may be attributed to two main aspects: (1) there were few diagonal cracks at each corner of the slab; (2) the higher reinforcement ratio of the slab may be beneficial to the force redistribution at the corners of the slab.

\subsection{Structural failure}

\subsubsection{Observations of the tests}

During the heating stage, the cracks' initiation and propagation on the top surfaces of the four concrete slabs were carefully observed and recorded. After the tests, visual signs of cracking 
and spalling were investigated and photographic evidence of the failure modes of the slabs is presented here.

\section{(1) Slab S1}

Fig. 13(a) shows the top view of the Slab S1 after the fire. Cracks were darkened with a brush to make them visible in the photograph. Clearly, two visible cracks on the top surface were in the central region of the slab. In contrast, there were several large diagonal cracks near to the four corners. These cracking patterns are similar to those observed in the Test 1 of Ref. [4].

As shown in Fig. 13 (b), during the early stage of the fire, popping noises were firstly heard from the in-plane restrained frame. At $20 \mathrm{~min}$, a crack (1) formed that was parallel to the south-north direction and at 1/2 span from the edge, $300 \mathrm{~mm}$ off the edge. After $30 \mathrm{~min}$, two cracks (2) and (3) normal to the edge occurred, which were at approximately 1/2 span. Water steam was emitted from the cracks as heating continued. Meanwhile, the corners of the slab started to curl upwards slightly. At about $40 \mathrm{~min}$, the diagonal cracks (4), (5), (6) and (7) on the top surface occurred. Some cracks formed a $45^{\circ}$ angle across the full depth to the top surface where they met the surface diagonal cracks. As the test progressed, the cracks on top surface of the slab continued to widen, particularly the diagonal cracks at the four corners. Meanwhile, a large amount of water and steam also seeped through the cracks, forming a puddle of water owing to the water accumulation in the middle of the slab. At about $120 \mathrm{~min}$, the puddle of water in the middle of the slab dried up.

Fig. 13(c) shows the bottom view of the slab after the fire. Slight concrete spalling occurred, and no reinforcing bars and no full-depth cracks were seen on the bottom surface of the slab, indicating that the slab had good fire-resistant performance in terms of both stability and integrity.

(2) Slabs S2, S3 and S4

Fig. 14(a) shows the cracking pattern on the top surface of the Slab S2. Clearly, the cracking pattern of the Slab S2 was quite different compared with the Slab S1. Particularly, one full 
depth crack formed across the whole length of the slab and the crack was about $3000 \mathrm{~mm}$ long. Although the restrained slab did not exceed the deflection limit of span/20, but the integrity failure criterion may be violated. As shown in Fig. 14(b), during the heating stage, several cracks (3), (4) and (5) of the Slab S2 firstly appeared on the top surface of the slab. Clearly, these cracks were parallel to the in-plane compressive direction and propagated from the middle of the slab towards the edges. Subsequently, diagonal cracks (1) occurred at the each corner of the slab. Similar to the Slab S1, a large amount of water and steam seeped through the cracks, forming a puddle of water in the middle of the slab.

The comparison indicates that the cracking patterns of the restrained slabs are significantly different compared with the unrestrained slab. As indicated in Ref. [24], complex stress states exist in the restrained concrete slabs under fire conditions. Due to the lateral restraint, the compressive mechanical strains of concrete were developed parallel to the restraint force direction. Therefore, additional tensile strains of concrete were generated in the direction perpendicular to the restraint force direction resulted from the influence of Poisson ratio. This is the main reason why the cracks were parallel to the in-plane compressive direction within the restraint slabs. As reported in Refs. [23-24, 32], for real structures under fire the stresses within the structural members are very complex and depend on both loading and support conditions.

Fig. 14(c) shows the spalling of the bottom surface of the Slab S2. Compared with the Slab S1, the spalling was relatively serious. Hence, it can be seen that the in-plane compressive force has an important effect on the crack direction, integrity and spalling of the restrained slab.

Figs. 15 and 16 show the failure models of the Slabs S3 and S4 during the heating stage. It can be seen that the cracking pattern of the Slab S3 is similar to the Slab S2. However, it is noted that no full-depth crack was visible on the bottom surfaces of the Slabs S3 and S4. This is due to the lower uni-axial in-plane compressive forces (Slab S3) and the higher reinforcement ratios (Slab S4). Also, it is evident that the number of cracks on the top surface of the slabs was clearly different among the three restrained slabs. Compared with the Slabs S2 and S3, the cracks on the top surface of the Slab S4 which has higher reinforcement ratio were relatively 
fewer, regardless of its higher uni-axial in-plane compressive forces applied during the test. No doubt, the fire-resistant performance (stability and integrity) of the Slab S4 is the best among the three restrained slabs. Based on these analyses, it can be concluded that increasing reinforcement ratio is beneficial to decrease the number of cracks and increase the fire-resistant performance, particularly to prevent the integrity of the slab.

\subsubsection{Discussions}

Based on the test results presented above, the comparisons of the cracking patterns for the four slabs indicate that the uni-axial in-plane compressive force has an important effect on the number and direction of the cracking within the slabs. More importantly, the failure mode of the restrained slabs is clearly different from that of the conventional simply-supported slabs. Hence, the conventional assumption of a yield-line failure mode may not be appropriate for modelling the fire-resistance of the uni-axial restrained slabs. However, it is noted that the current simplified methods for predicting the fire behaviour of reinforced concrete slabs $[2,25,26]$ were based on the assumption of the yield-line pattern.

Over the past decade, many researchers have developed numerical models for predicting the structural behaviour of reinforced concrete slabs in fire. These models are all based on a continuum approach in which local concrete failure is represented by "smeared" cracking. These models can predict the global behaviour of concrete slabs subjected to large deflection with reasonable accuracy. However, they cannot predict localised failures due to individual large cracks through the slab thickness, as observed in the present tests (see Fig. 14(a)). It is clear that when this type of crack formed within the slabs in fire the criterion of structural integrity may be violated, although the structural stability may still be maintained. It is therefore important to develop the numerical models in which both structural stability and integrity can be assessed, so that a meaningful failure condition can be identified by the numerical analysis.

Hence, according to the recent studies [35], further work involving comprehensive thermal and structural analysis is currently being carried out by the authors to fully understand the fire 
induced structural response of the restrained slabs. In addition, the experimental results presented in this paper can be used to validate the theoretical methods developed.

\section{Conclusions}

In this paper, four large scale fire tests on the reinforced concrete slabs, under combined uni-axial in-plane and out-of-plane loading conditions with vertical restraint at four corners of the slabs, are presented for the first time. The research was mainly focused on the quantitative relationship between horizontal restrained force and deformation, cracking pattern and spalling of the slabs in fire. Based on the test results, the following conclusions can be drawn as:

(1) During the heating and cooling stages, the vertical and horizontal deflections of the slabs with combined horizontal uni-axial in-plane and vertical out-of-plane forces are larger than those of the slabs without uni-axial in-plane restraint force. In addition, the presence of uni-axial in-plane compression restraint force causes higher deflection rate during the heating stage and smaller deflection recovery rate during the cooling stage for the slab.

(2) The cracking patterns of the three restrained slabs are similar to each other and are considerably different from the slab without restraint force. For the restrained slabs, the number, direction and position of cracks are significantly dependent on the uni-axial in-plane compression forces and the steel reinforcement ratio.

(3) The restrained slabs with large uni-axial in-plane forces tend to fail by integrity failure resulted from the full-depth crack of the slab as shown in Slab 2 (see Fig. 14). For the restrained slabs, the reduction in the number of cracks can be achieved efficiently by increasing the reinforcement ratio.

(4) Compared to the cracking patterns of Slabs S2, S3 and S4, for increasing the fire-resistance performance of the restrained slabs, it is important to prevent the full-depth crack formed within concrete slabs and compressive failure of concrete at the corners of the slabs. Hence, the reasonable integrity failure criteria should be established for considering the adverse effect of the large uni-axial in-plane compressive forces and the favourable effect of the high reinforcement ratio. 


\section{Acknowledgements}

This research was supported by the National Natural Science Foundation of China (Grant No. 51408594) and Fundamental Research Funds for the Central Universities (Grant No.2014QNA78). The authors gratefully acknowledge the supports.

\section{References}

[1] Bailey C.G, Toh W.S., Behaviour of concrete floor slabs at ambient and elevated temperatures, Fire Safety Journal, 2007, 42: 425-436.

[2] Bailey C.G., Toh W.S., Small-scale concrete slab tests at ambient and elevated temperatures, Engineering Structures, 2007, 29: 2775-2791.

[3] Lim L., Wade C., Experimental fire tests of two-way concrete slabs, Fire Engineering Research Report 02/12, University of Canterbury and BRANZ Ltd, New Zealand, 2002.

[4] Yang Z.N., Dong Y.L., Xu W.J., Fire tests on two-way concrete slabs in a full-scale multi-storey steel-framed building, Fire Safety Journal, 2013, 58: 38-48.

[5] Wang Y., Dong Y.L., Li B., Zhou G.C., A fire test on continuous reinforced concrete slabs in a full-scale multi-story steel-framed building, Fire Safety Journal, 2013, 61: 232-242.

[6] Dong Y.L., Zhu C.J., Limit load carrying capacity of two-way slabs with two edges clamped and two edges simply supported in fire, Journal of Structural Engineering, 2010, 137: 1182-1192.

[7] Li B., Dong Y., Lou Y.J., A fire test of continuous panels in a full-scale steel-framed structure, Engineering Mechanics, 2015, 32: 145-153. (in Chinese).

[8] Lim L., Buchanan A., Moss P., Franssen J.M., Computer modeling of restrained reinforced concrete slabs in fire conditions, Journal of Structural Engineering, 2004, 130: 1964-1971.

[9] Selvaggio S. L., Carlson C. C., Effect of restraint on fire resistance of prestressed concrete. American Society for Testing and Materials, STP 344, 1963, 1-25.

[10] Issen, L. A, Gustaferro, A. H, and Carlson, C. C. Fire tests of concrete members: An improved method for estimating thermal restraint forces. Fire Test Performance, ASTM, 1970, 153-185.

[11] Anderberg Y., Forsen N.E., Fire resistance of concrete structures, Division of Structural Mechanics and Concrete Construction, Lund Institute of Technology, Lund, Sweden, 1982.

[12] Lin T.D., Zwiers R.I., Shirley S.T., Burg R.G., Fire test of concrete slab reinforced with epoxy-coated bars, ACI Structural Journal, 1989, 86:156-162.

[13] Cooke G.M.E., Results of tests on end-restrained reinforced concrete floor strips exposed to standard fires, Report Prepared for the Construction Directorate of the Department of the Environment, Fire Research Station, Hertfordshire UK, 1993. 
[14] Foster S., Bailey C.G., Burgess I.W., Plank, R.J., Experimental behaviour of concrete floor slabs at large displacements, Engineering Structures, 2004, 26: 1231-1247.

[15] Foster S., Burgess I.W., Plank R.J., Experimental behaviour of model-scale concrete floor slabs at large displacement and high temperatures, Proc. Second International Conference on Steel and Composite Structures, 2004, 1268-1282.

[16] Wang B., Dong Y.L., Experimental research of four-edge simple support two-way reinforced concrete slab under fire, Journal of Building Structures, 2009, 30: 23-33. (in Chinese).

[17] Wang B., Dong Y.L., Experimental study of two-way reinforced cocnrete slabs under fire, China Civil Engineering Journal, 2010, 43: 53-62. (in Chinese).

[18] Zhu C.J., Studies on fire resistance properties of full-scale two-way reinforced concrete slabs, $\mathrm{PhD}$ thesis, Harbin Institute of Technology, Harbin, 2012.

[19] Wang Y., Tensile membrane action in slabs and its application to the Cardington fire tests, Proceedings of the Second Cardington Conference, 1996, 12-14.

[20] Lamont S., Usmani A., Drysdale D., Heat transfer analysis of the composite slab in the Cardington frame fire tests, Fire Safety Journal, 2001, 36: 815-839.

[21] Huang Z., Burgess I.W., Plank R.J., Modeling membrane action of concrete slabs in composite buildings in fire. I: Theoretical development, Journal of Structural Engineering, 2003, 129: 1093-1102.

[22] Huang Z., Burgess I.W., Plank R.J., Modeling membrane action of concrete slabs in composite buildings in fire. II: Validations, Journal of Structural Engineering, 2003, 129: 1103-1112.

[23] Cameron N.J.K, Usmani A.S., New design method to deterimine the membrane capcity of laterally restrained composite floor slabs in fire Part 1: Theory and method, The Structural Engineer, 2005, 83(19): 28-33.

[24] Usmani A.S., Rotter J.M., Lamont S., Sanad A.M., Gillie M.. Fundamental principles of structural behaviour under thermal effects, Fire Safety Journal, 2001, 36: 721-744.

[25] Li G.Q., Guo S.X., Zhou H.S., Modeling of membrane action in floor slabs subjected to fire, Engineering Structures, 2007, 29: 880-887.

[26] Zhang N.S., Li G. Q., An innovative analytical method for the membrane action of composite floor slabs in fire, China Civil Engineering Journal, 2009, 42(3): 29-35.(in Chinese)

[27] Dong Y.L., Fang Y.Y., Determination of tensile membrane effects by segment equilibrium, Magazine of Concrete Research, 2010, 62(1): 17-23.

[28] Wang Y., Dong Y.L., Yuan G.L., Zou C.Y., New failure criterion to determine the load carrying capacity of two-way reinforced concrete slabs, Advances in Structural Engineering, 2015, 18(2): 221-235.

[29] Standard Methods for Testing of Concrete Structures of China (GB50152-92), (1992), Beijing. (in Chinese). 
[30] ASTM Standard methods of fire test of building construction and materials. Test Method. West Conshohocken, PA: American Society for Testing and Materials; 2001. p. E119-E201.

[31] Lim L., Buchanan A.H., Moss P.J., Restraint of fire-exposed concrete floor systems, Fire and Materials, 2004, 28: 95-125.

[32] Gillie M., Usmani A.S., Rotter J.M., Bending and membrane action in concrete slabs, Fire and Materials, 2004, 28: 139-157.

[33] BS. Fire tests on building materials and structures-Part 20: Method from determination of the fire resistance of elements of construction (general principles), BS476-3:1987, BSI, UK, 1987.

[34] Omer E., Izzuddin B. A., Elghazouli A. Y., Failure of lightly reinforced concrete floor slabs with planar edge restraints under fire, Journal of Structural engineering, 2009, 135(9):1068-1080.

[35] Liao F., Huang Z., An extended finite element model for modelling localised fracture of reinforced concrete beams in fire, Computers and Structures, 2015, 152: 11-26. 


\section{Figure and table captions}

Table 1 Average furnace temperatures of the four tested slabs during the heating stage $\left({ }^{\circ} \mathrm{C}\right)$.

Table 2 Average furnace temperatures of the four tested slabs during the cooling stage $\left({ }^{\circ} \mathrm{C}\right)$

Fig. 1 Self-design furnace (all dimensions in $\mathrm{mm}$ ).

Fig. 2 The details of thermocouples' distribution within the slab (all dimensions in $\mathrm{mm}$ ).

Fig. 3 Layout of the vertical and horizontal displacement transducers in each concrete slab (all dimensions in $\mathrm{mm}$ ).

Fig. 4 The details of horizontal uni-axial in-plane loading and vertical support systems (all dimensions in $\mathrm{mm}$ ).

Fig. 5 Furnace temperature-time curves of: (a) Slab S1, (b) Slab S2, (c) Slab S3 and (d) Slab S4.

Fig.6 Temperature distributions along the thickness of the Slabs: (a) Slab S1-T4, (b) Slab S2-T1, (c) Slab S3-T3 and (d) Slab S4-T9.

Fig.7 Temperatures of the reinforcing steels of: (a) Slab S1, (b) Slab S2, (c) Slab S3 and (d) Slab S4.

Fig. 8 Vertical out-of-plane deflections-time curves of the Slabs: (a) Slab S1, (b) Slab S2, (c) Slab S3 and (d) Slab S4.

Fig.9 Out-of-plane deflections-furnace temperature curves of the slabs: (a) Slab S1, (b) Slab S2, (c) Slab S3 and (d) Slab S4.

Fig.10 Horizontal deflections of the slabs: (a) Slab S1, (b) Slab S2, (c) Slab S3 and (d) Slab S4.

Fig. 11 Measured uni-axial in-plane restraint forces in the slabs: (a) Slab S3 and (b) Slab S4.

Fig.12 Restrained forces at the corners of the slabs: (a) Slab S1, (b) Slab S2, (c) Slab S3 and (d) Slab S4.

Fig. 13 Failure models of the Slab S1: (a) Cracking pattern, (b) Cracks' development and (c) Spalling.

Fig. 14 Failure models of the Slab S2: (a) Cracking pattern, (b) Cracks' development and (c) Spalling.

Fig. 15 Failure models of the Slab S3: (a) Cracking pattern, (b) Cracks' development.

Fig. 16 Failure models of the Slab S4: (a) Cracking pattern, (b) Cracks' development. 


\section{Tables:}

Table 1 Average furnace temperatures of the four tested slabs during the heating stage $\left({ }^{\circ} \mathrm{C}\right)$

\begin{tabular}{|c|c|c|c|c|c|c|c|c|c|c|c|c|c|c|c|c|c|c|c|c|c|c|c|c|}
\hline $\begin{array}{l}\text { Time } \\
(\min )\end{array}$ & 0 & 1 & 3 & 5 & 7 & 10 & 15 & 20 & 30 & 40 & 50 & 60 & 70 & 80 & 90 & 100 & 110 & 120 & 130 & 140 & 150 & 160 & 170 & 180 \\
\hline S1 & 29 & 54 & 312 & 420 & 517 & 514 & 586 & 646 & 710 & 754 & 789 & 825 & 841 & 850 & 797 & 841 & 762 & 799 & 784 & 767 & 865 & 833 & 886 & 721 \\
\hline S2 & 26 & 27 & 27 & 53 & 365 & 503 & 614 & 655 & 722 & 767 & 805 & 833 & 854 & 878 & 890 & 896 & 901 & 841 & 789 & 806 & 810 & 823 & 808 & 798 \\
\hline S3 & 25 & 24 & 235 & 441 & 517 & 561 & 601 & 638 & 709 & 773 & 816 & 851 & 840 & 836 & 842 & 852 & 855 & 863 & 887 & 883 & 902 & 896 & 924 & 919 \\
\hline S4 & 29 & 1879 & 464 & 539 & 566 & 589 & 620 & 644 & 691 & 712 & 747 & 774 & 798 & 807 & 806 & 794 & 839 & 852 & 839 & 835 & 834 & 847 & 844 & 837 \\
\hline
\end{tabular}

Table 2 Average furnace temperatures of the four tested slabs during the cooling stage $\left({ }^{\circ} \mathrm{C}\right)$

\begin{tabular}{|c|c|c|c|c|c|c|c|c|c|c|c|c|c|c|c|c|c|c|c|c|c|c|c|c|}
\hline $\begin{array}{l}\text { Time } \\
\text { (min) }\end{array}$ & 182 & 185 & 190 & 195 & 200 & 210 & 220 & 230 & 240 & 250 & 260 & 270 & 280 & 290 & 300 & 310 & 320 & 330 & 340 & 350 & 360 & 370 & 380 & 400 \\
\hline S1 & 654 & 571 & 496 & 446 & 409 & 356 & 316 & 287 & 263 & 243 & 227 & 212 & 199 & 187 & 176 & 167 & 158 & 150 & 142 & 136 & 130 & 124 & 118 & 113 \\
\hline $\mathrm{S} 2$ & 787 & 756 & 658 & 502 & 438 & 362 & 310 & 276 & 250 & 232 & 212 & 198 & 185 & 174 & 164 & 153 & 145 & 134 & 132 & 121 & 116 & 108 & 104 & 102 \\
\hline S3 & 902 & 762 & 596 & 520 & 462 & 376 & 322 & 276 & 238 & 210 & 189 & 173 & - & - & - & - & - & - & - & - & - & - & - & - \\
\hline S4 & 838 & 843 & 647 & 526 & 464 & 387 & 337 & 302 & 274 & 250 & 233 & 217 & 202 & 190 & 179 & 169 & 160 & 152 & 142 & 134 & 127 & 120 & 114 & 108 \\
\hline
\end{tabular}




\section{Figures}

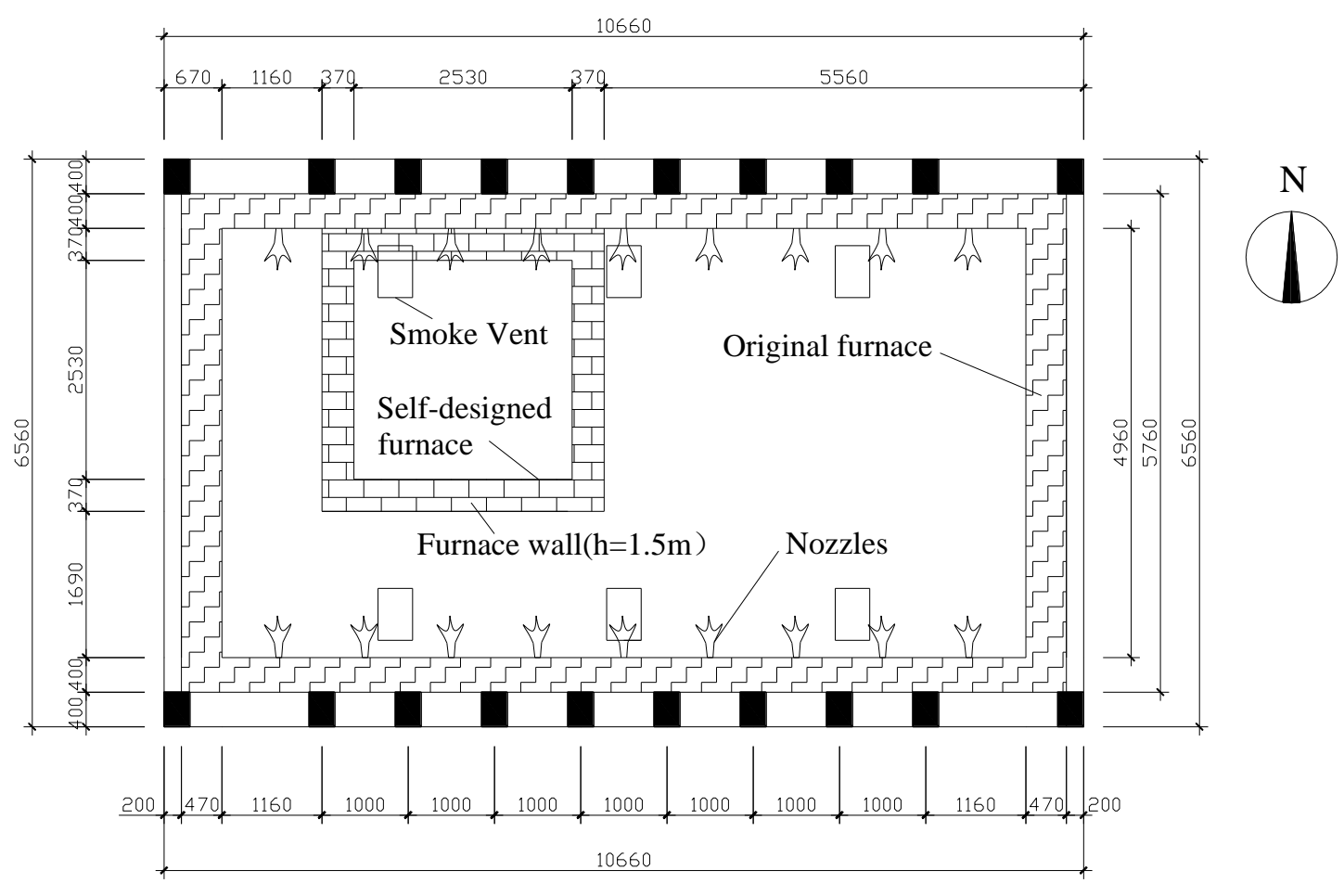

(a) Plan view of the furnace

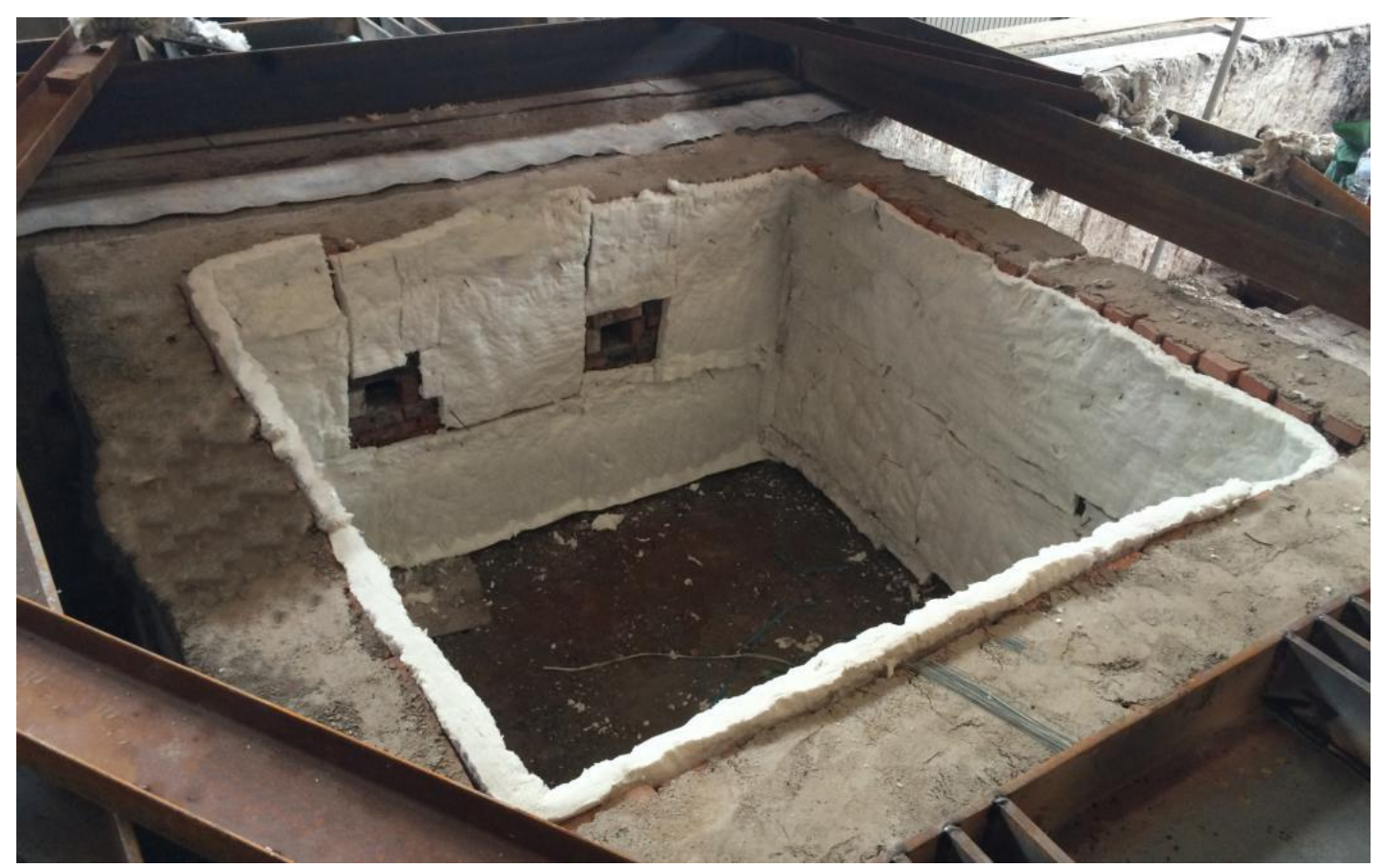

(b) External view of the self-designed furnace

Fig. 1 Self-design furnace (all dimensions in $\mathrm{mm}$ ). 

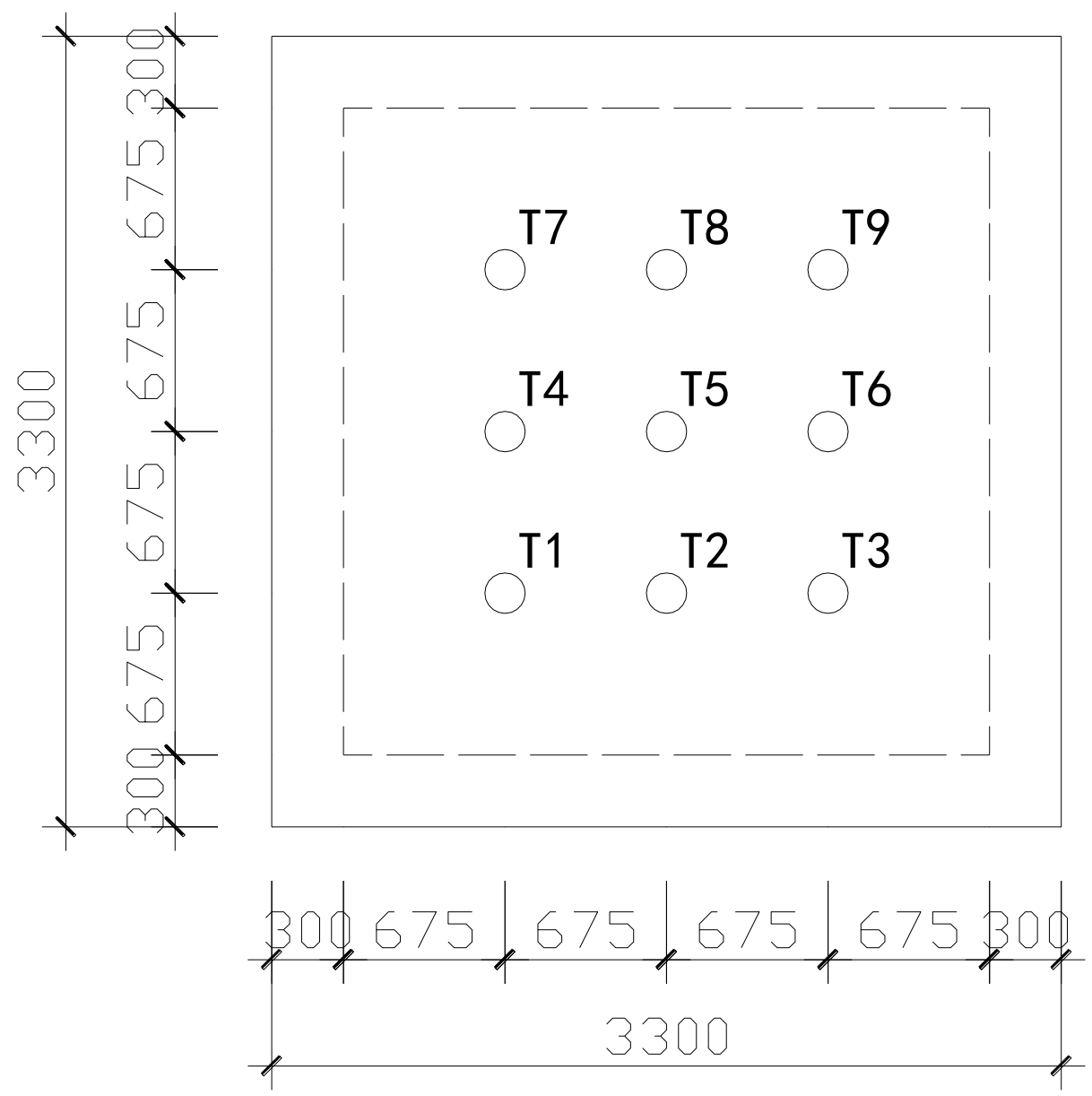

(a) Typical layout of thermocouples in the concrete slab

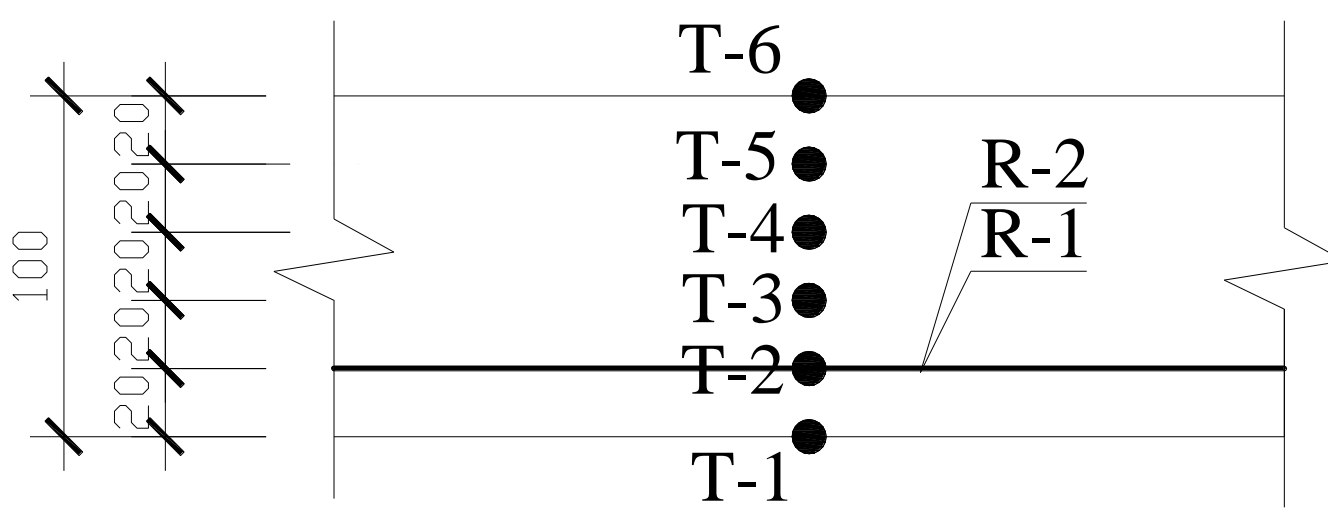

(b) Thermocouples across the full-depth of each slab

Fig. 2 The details of thermocouples' distribution within the slab (all dimensions in mm). 


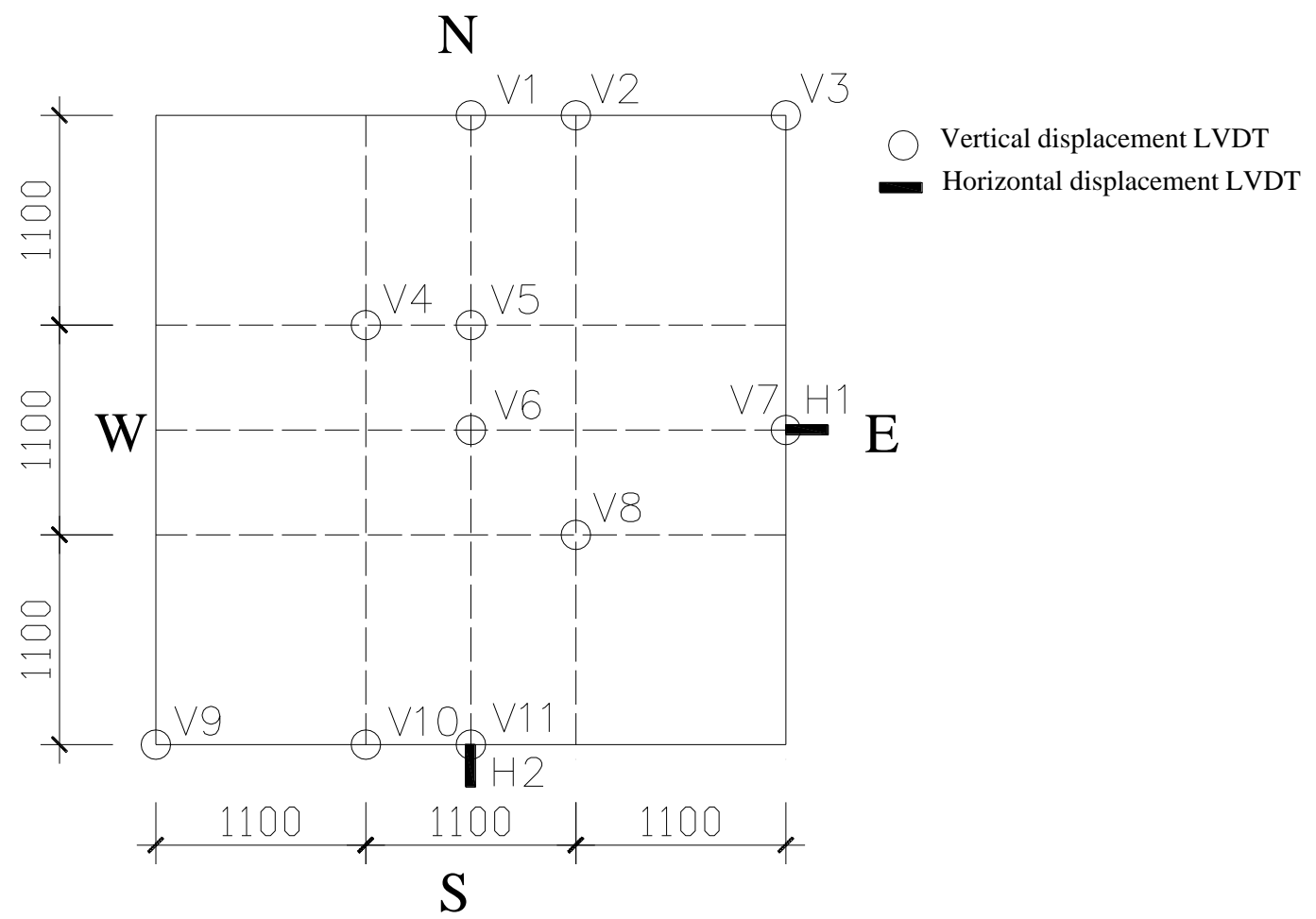

Fig. 3 Layout of the vertical and horizontal displacement transducers in each concrete slab (all dimensions in $\mathrm{mm}$ ).

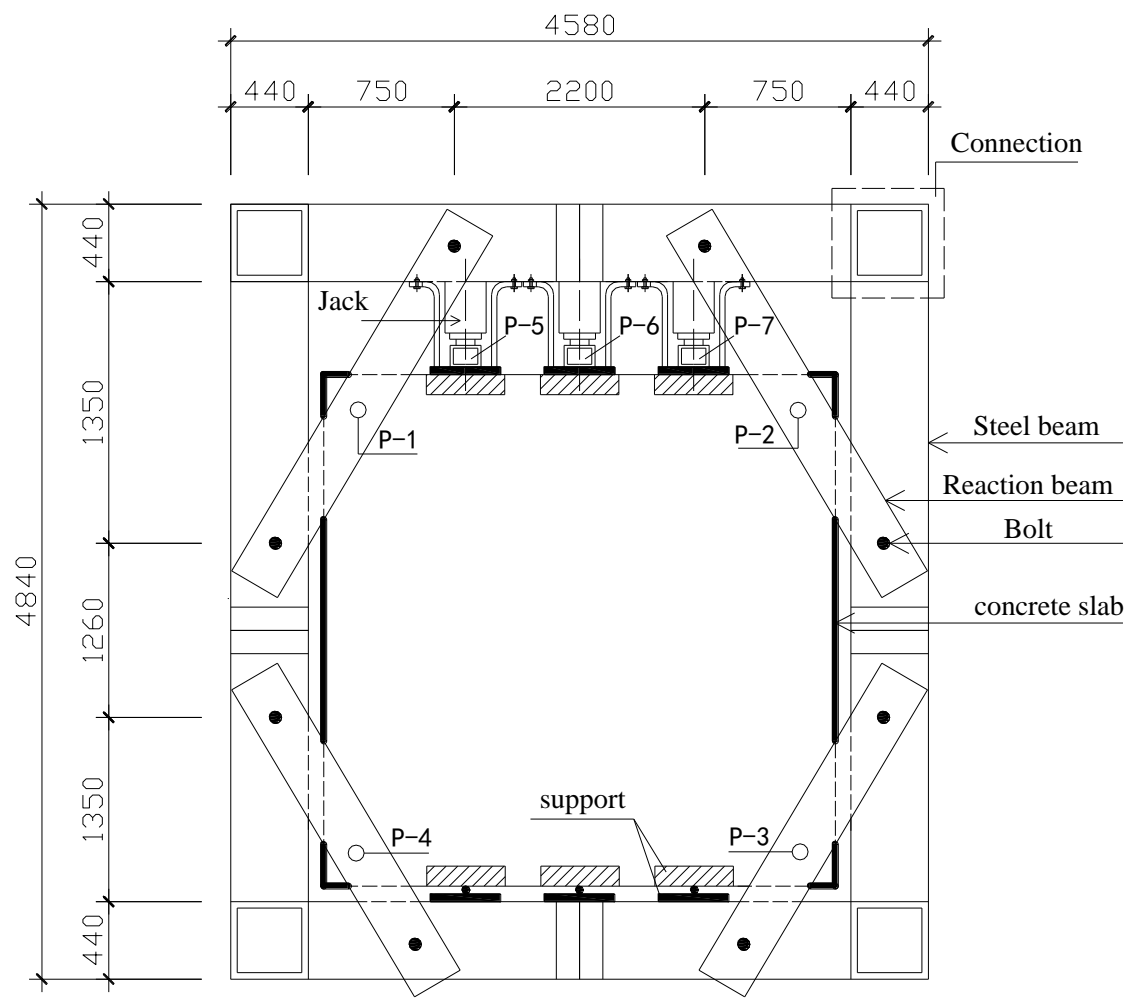

(a) Plan view of uni-axial in-plane loading frame 


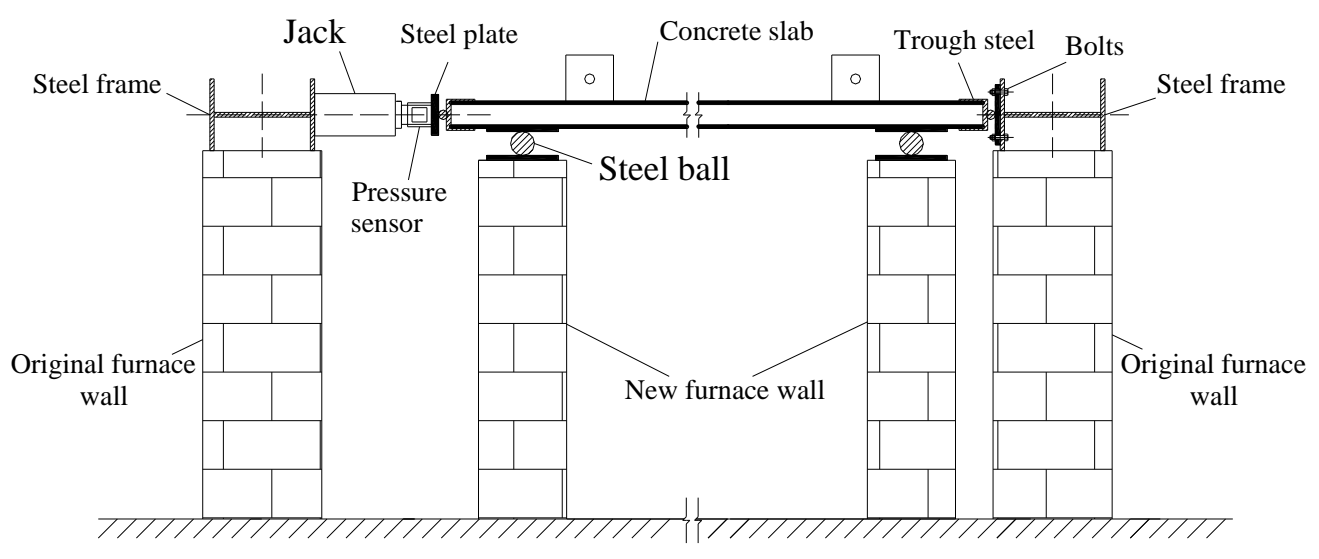

(b) Cross-section view of uni-axial in-plane loading frame

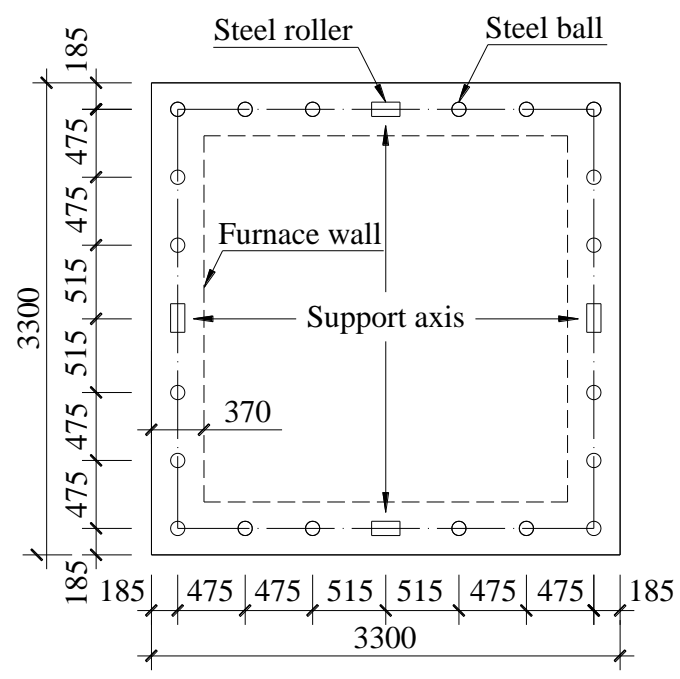

(c) Configuration of vertical edge supports

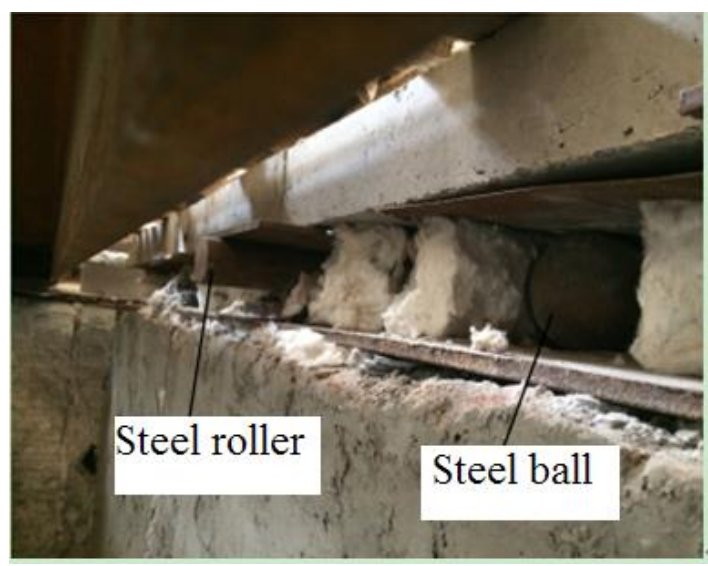

(d) Configuration of steel balls and steel rollers

Fig. 4 The details of horizontal uni-axial in-plane loading and vertical support systems (all dimensions in $\mathrm{mm})$. 


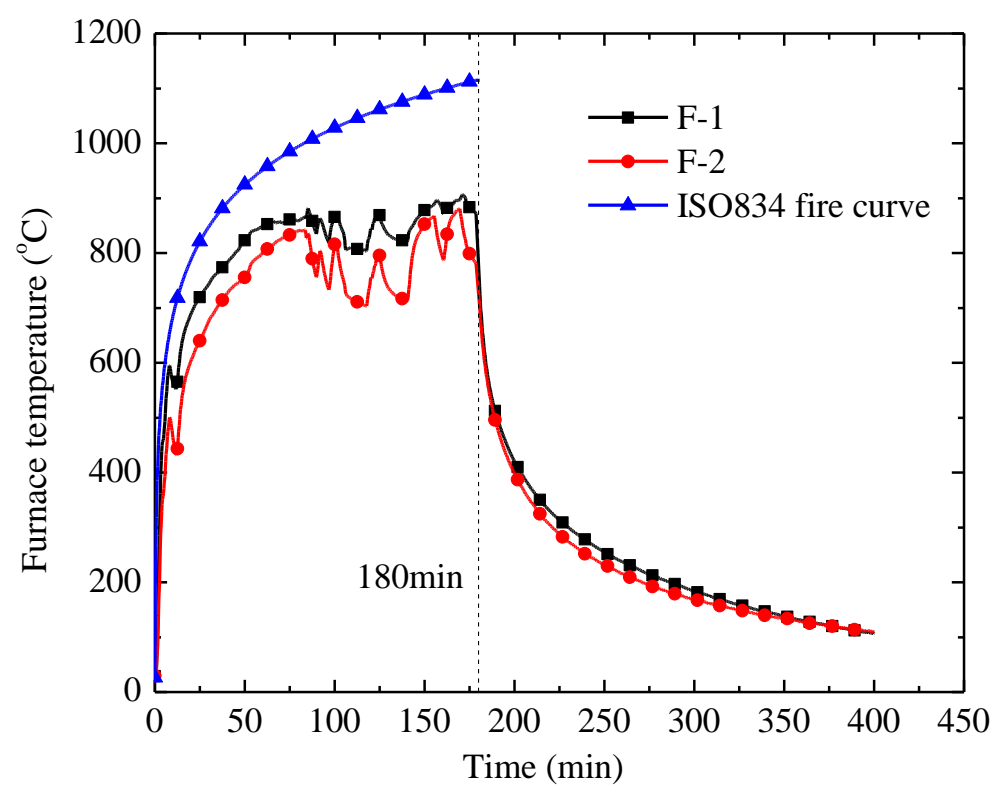

(a) Slab S1

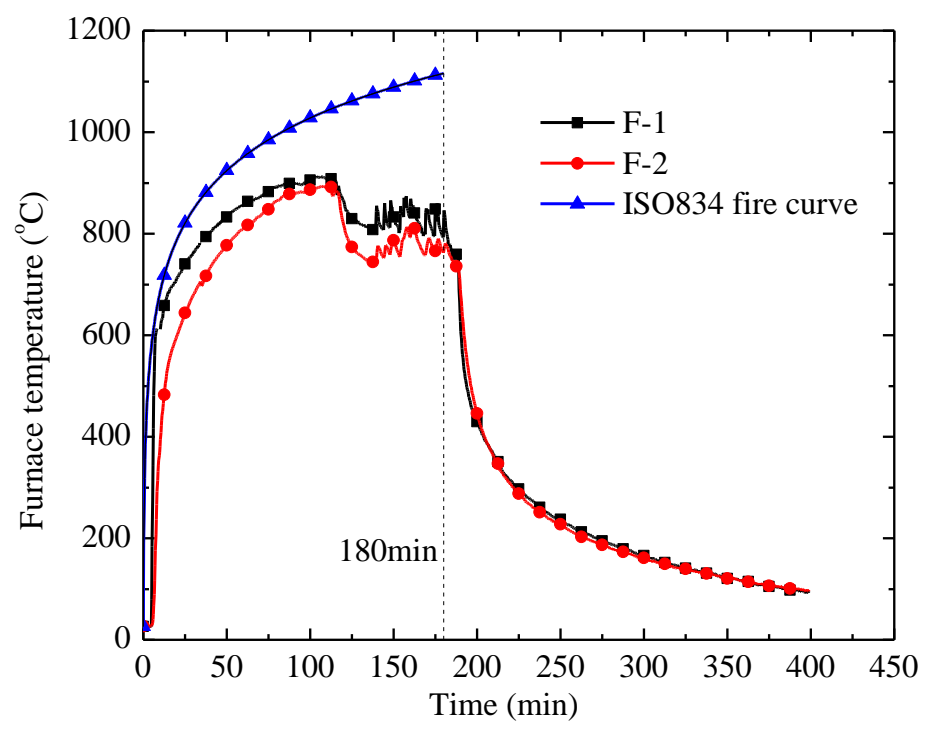

(b) Slab S2 


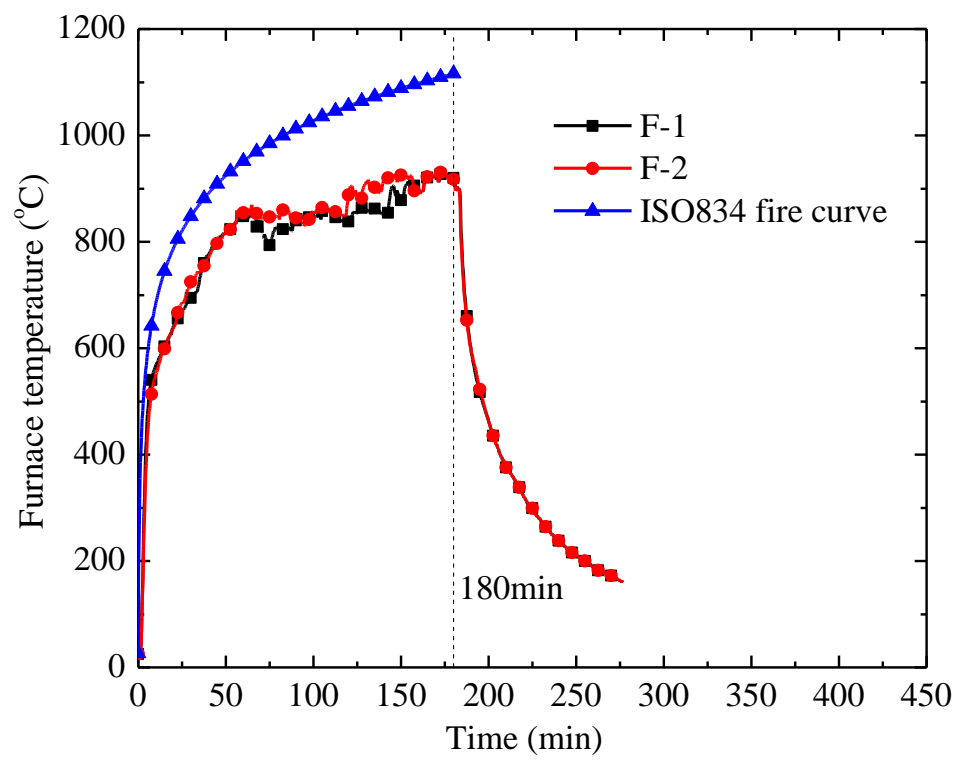

(c) Slab S3

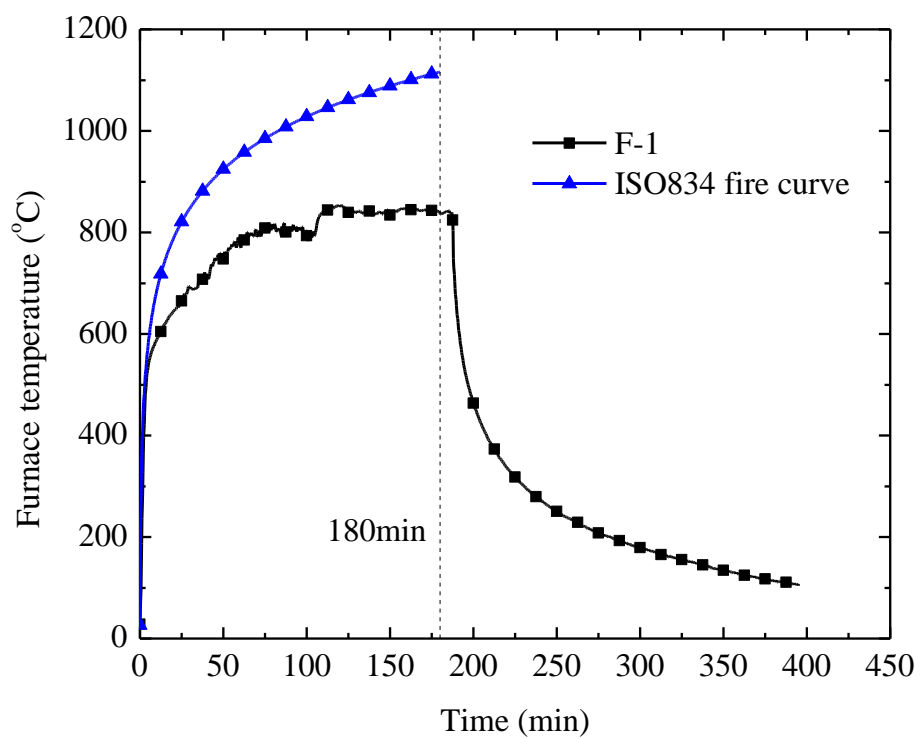

(d) Slab S4

Fig. 5 Furnace temperature-time curves of: (a) Slab S1, (b) Slab S2, (c) Slab S3 and (d) Slab S4. 


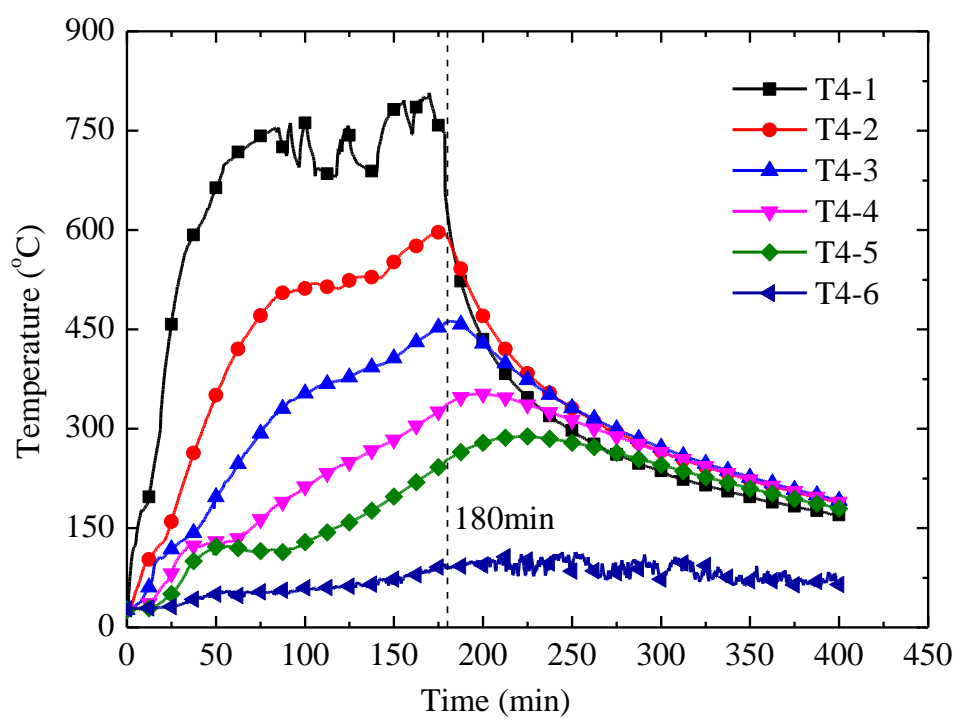

(a) Slab S1-T4

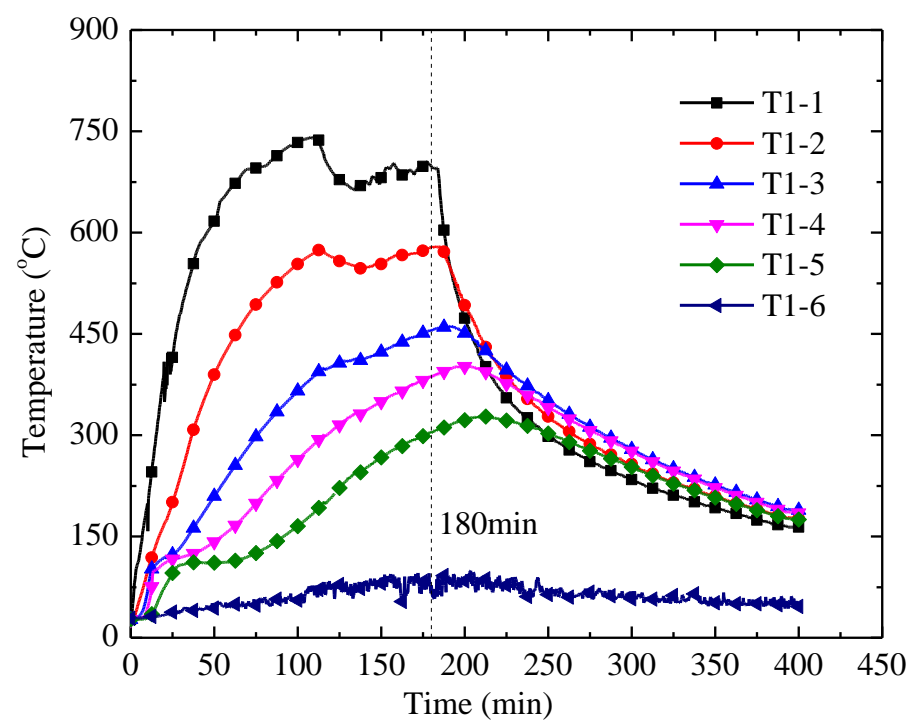

(b) Slab S2-T1 


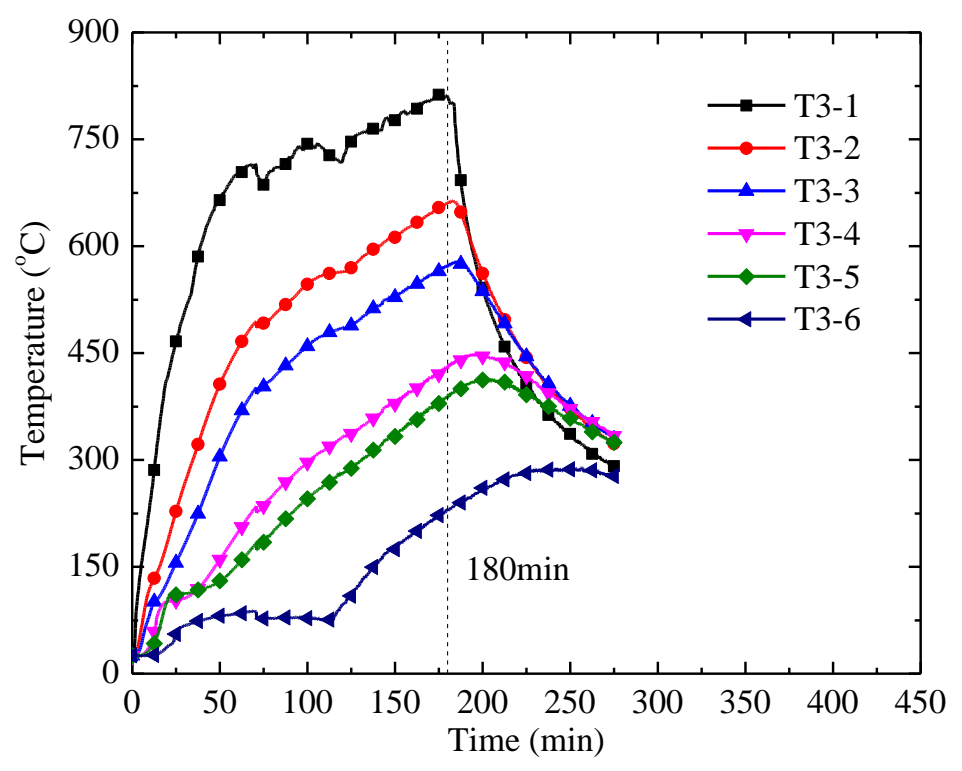

(c) Slab S3-T3

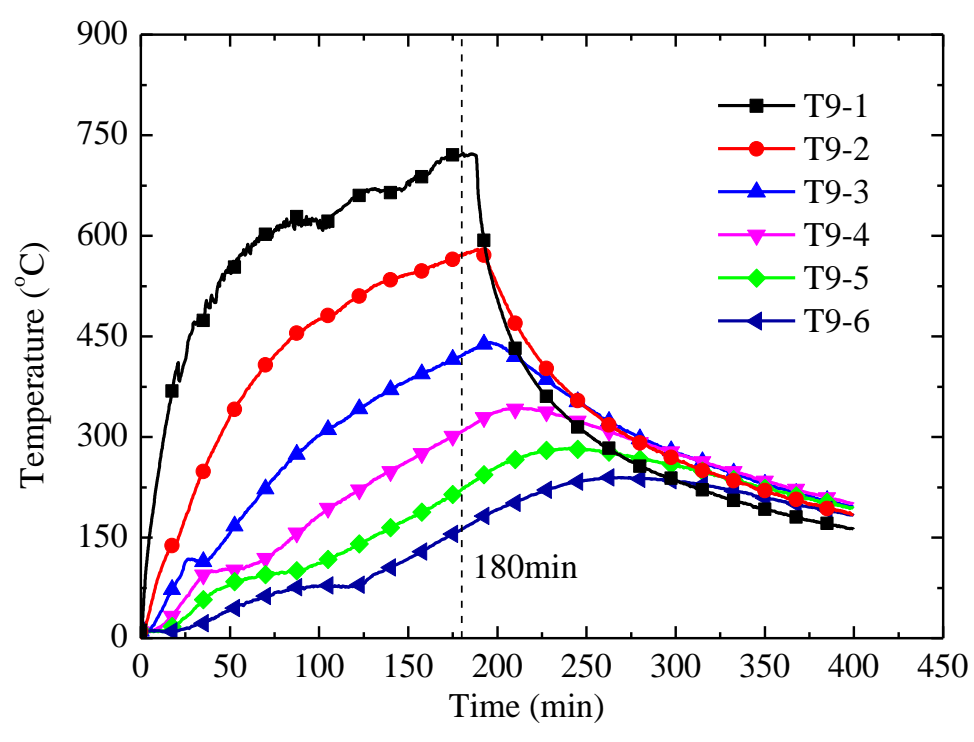

(d) Slab S4-T9

Fig.6 Temperature distributions along the thickness of the Slabs: (a) Slab S1-T4, (b) Slab S2-T1, (c) Slab S3-T3 and (d) Slab S4-T9. 


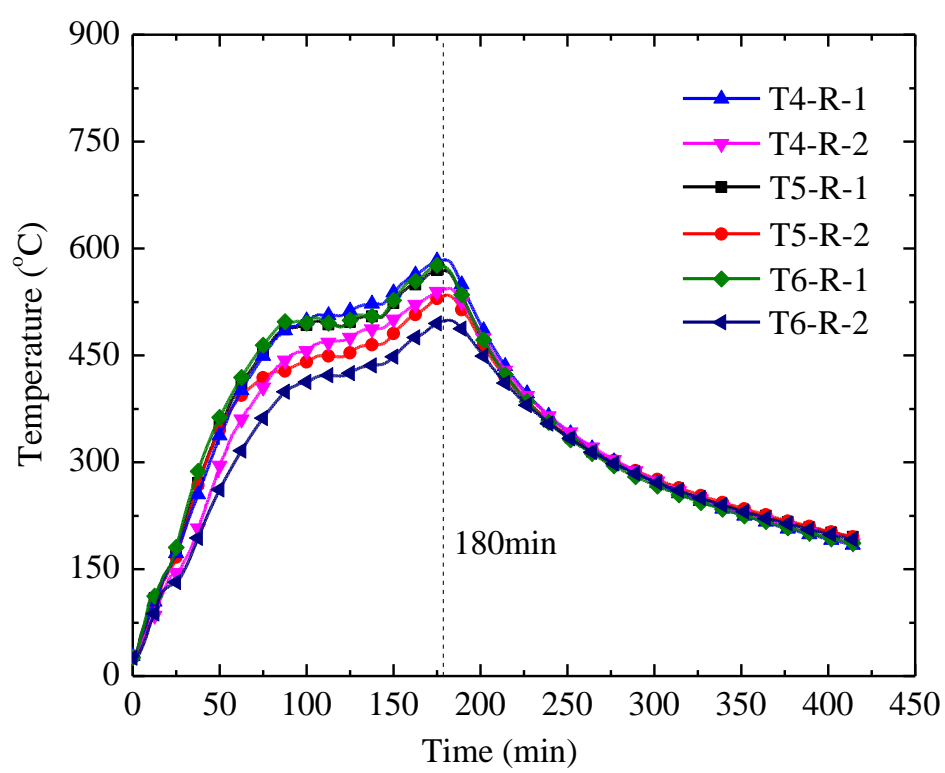

(a) Slab S1

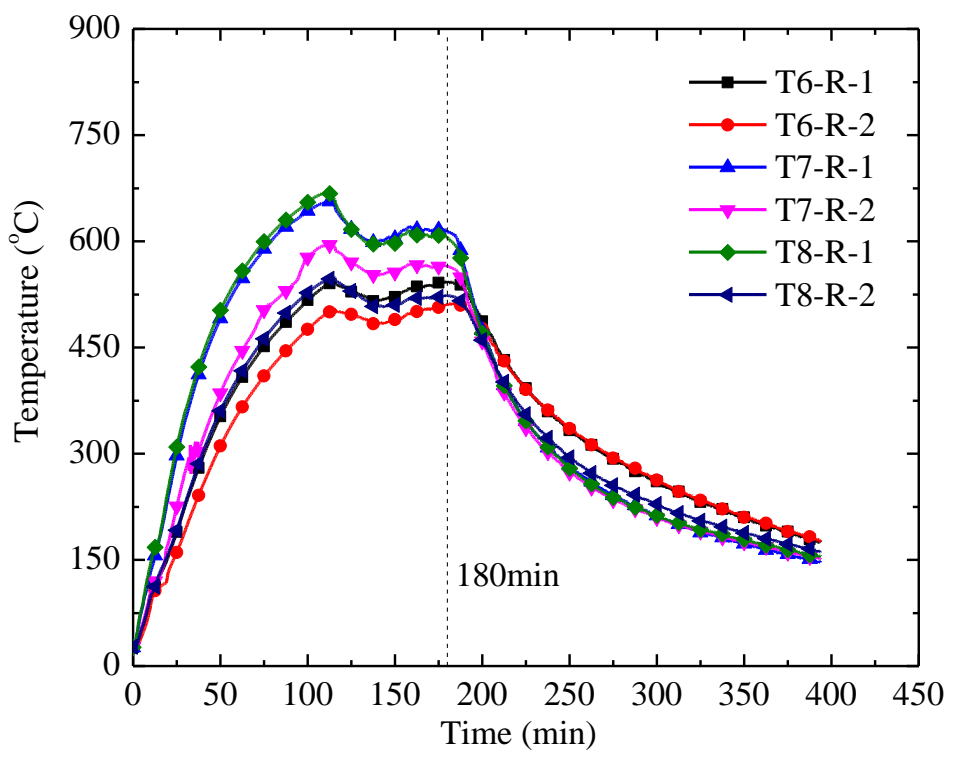

(b) Slab S2 


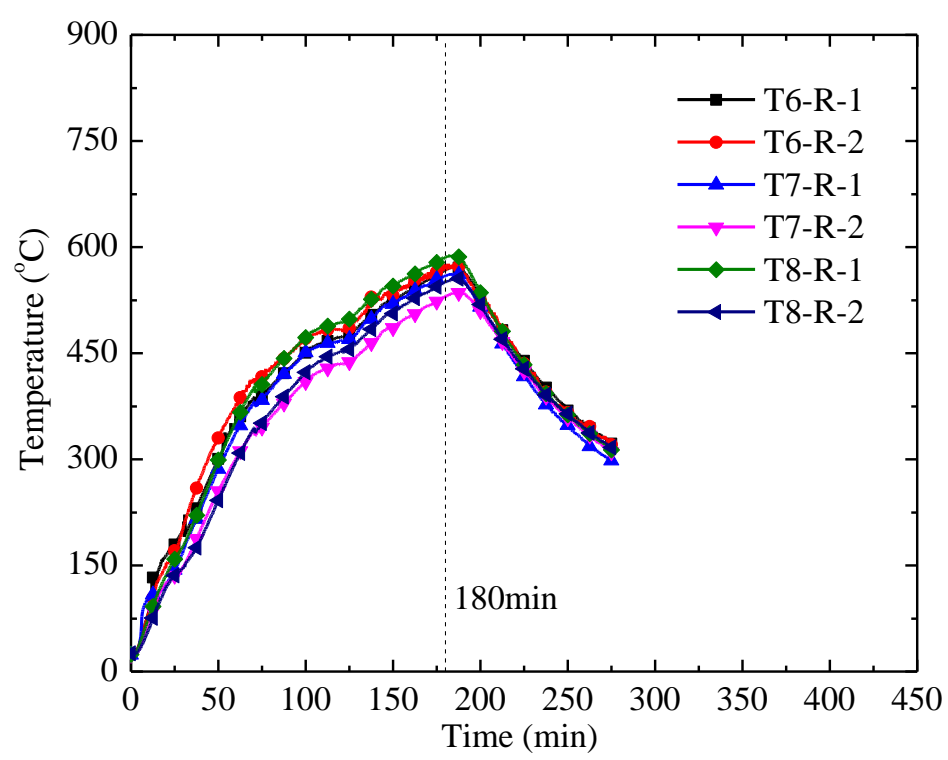

(c) Slab S3

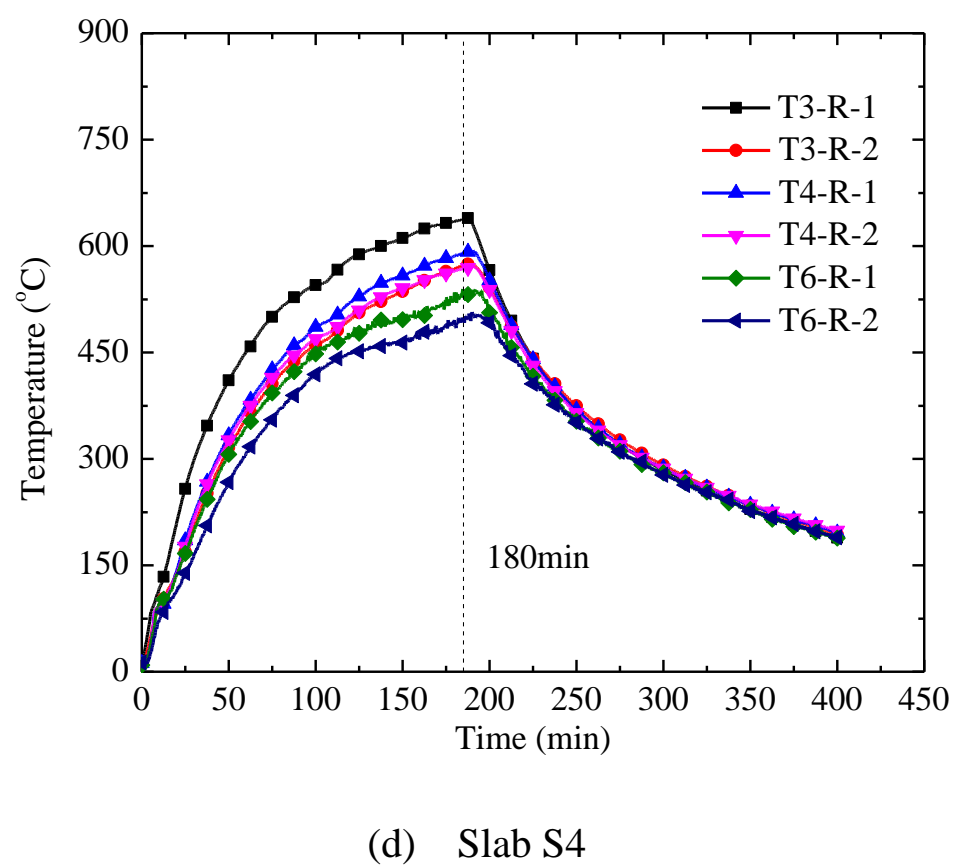

Fig.7 Temperatures of the reinforcing steels of: (a) Slab S1, (b) Slab S2, (c) Slab S3 and (d) Slab S4. 


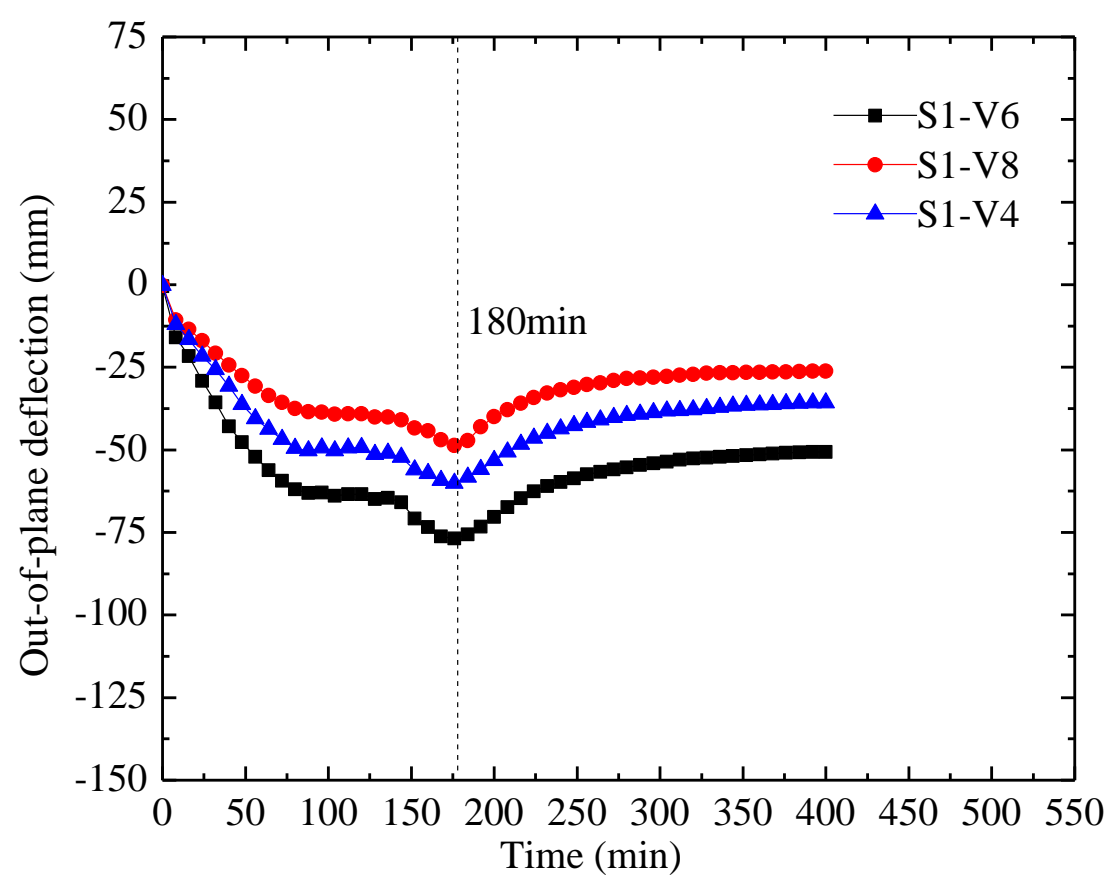

(a) Slab S1

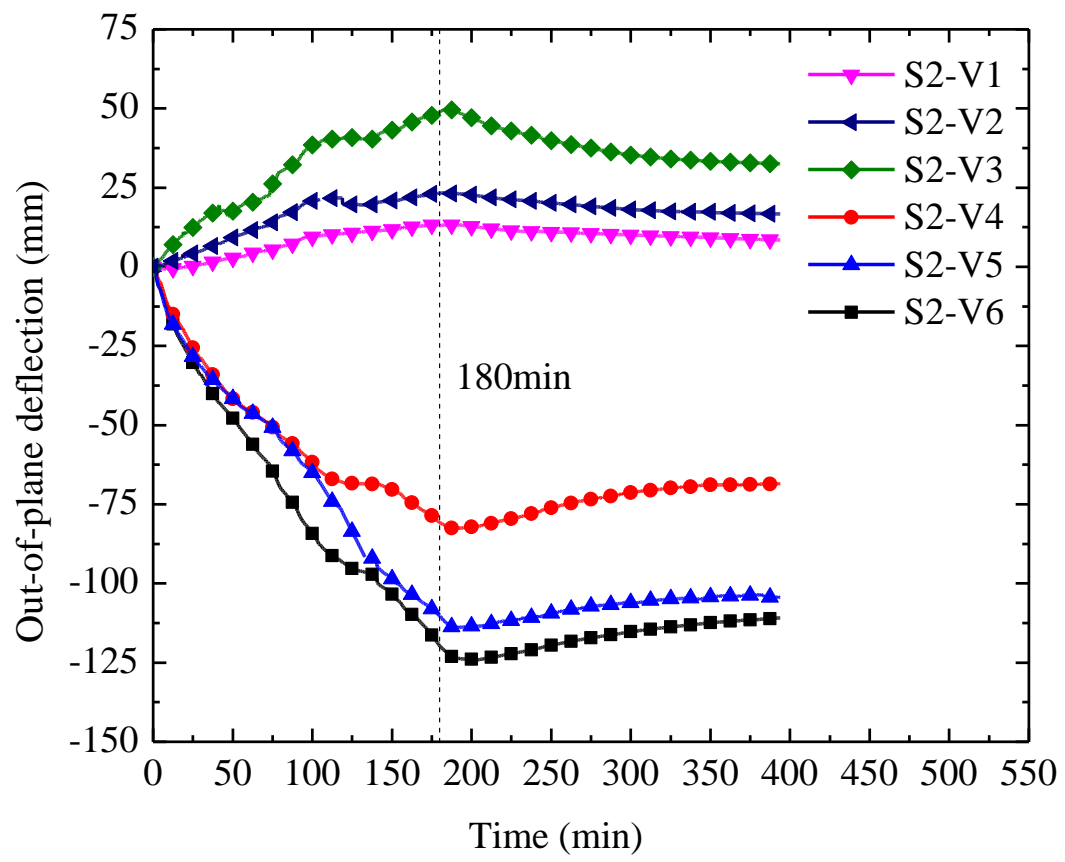

(b) Slab S2 


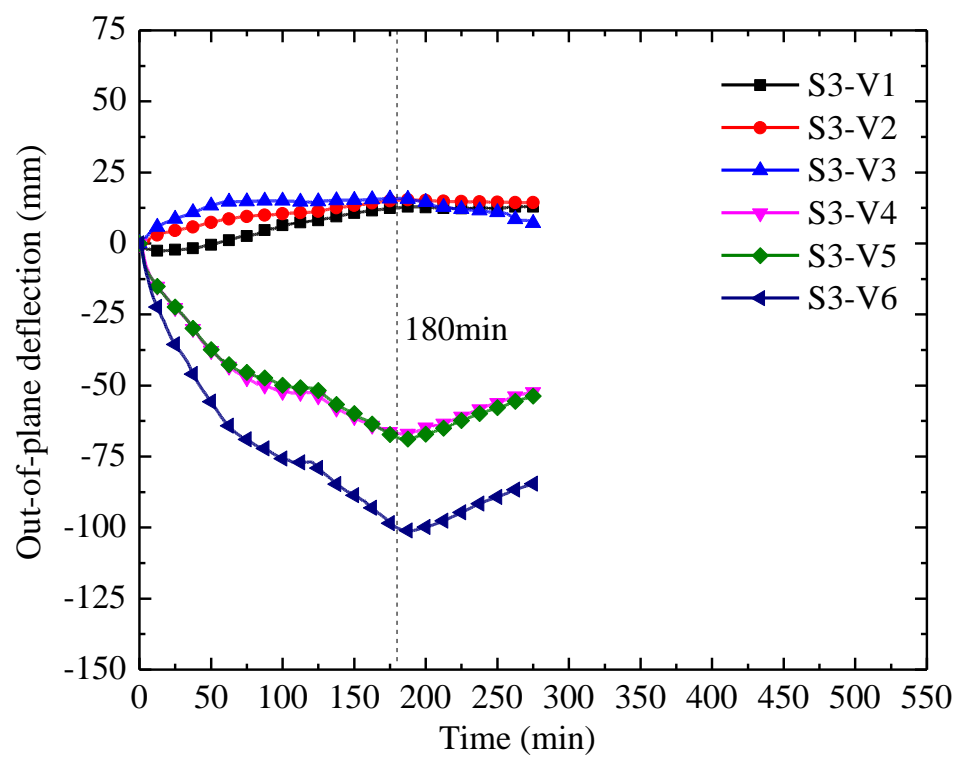

(c) Slab S3

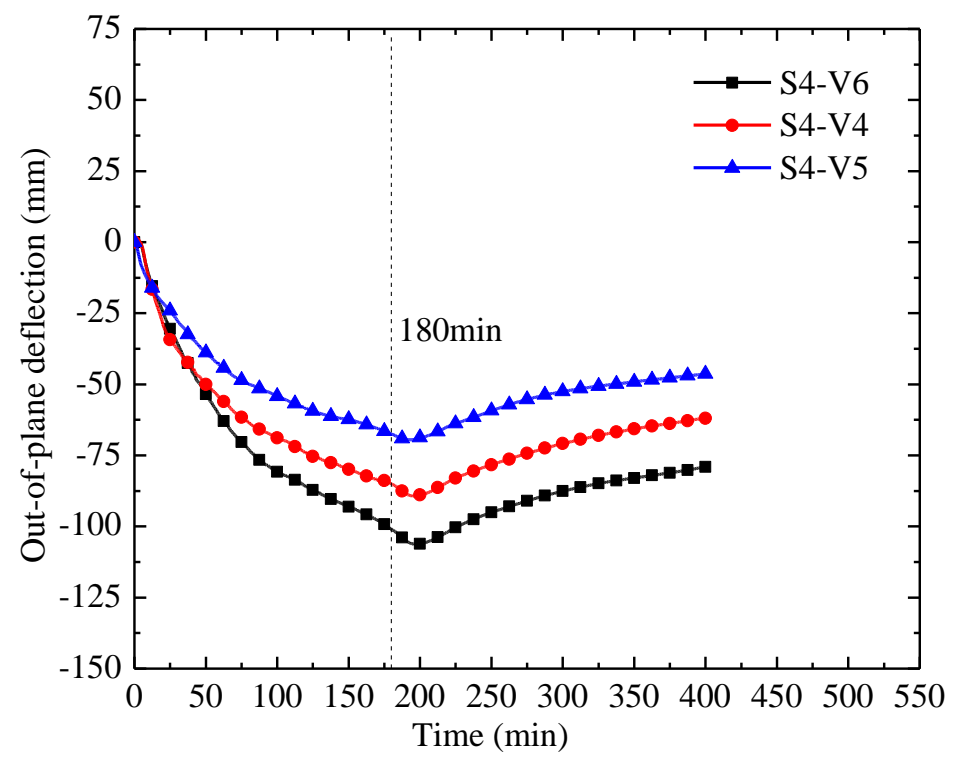

(d) Slab S4

Fig. 8 Vertical out-of-plane deflections-time curves of the Slabs: (a) Slab S1, (b) Slab S2, (c) Slab S3 and (d) Slab S4. 


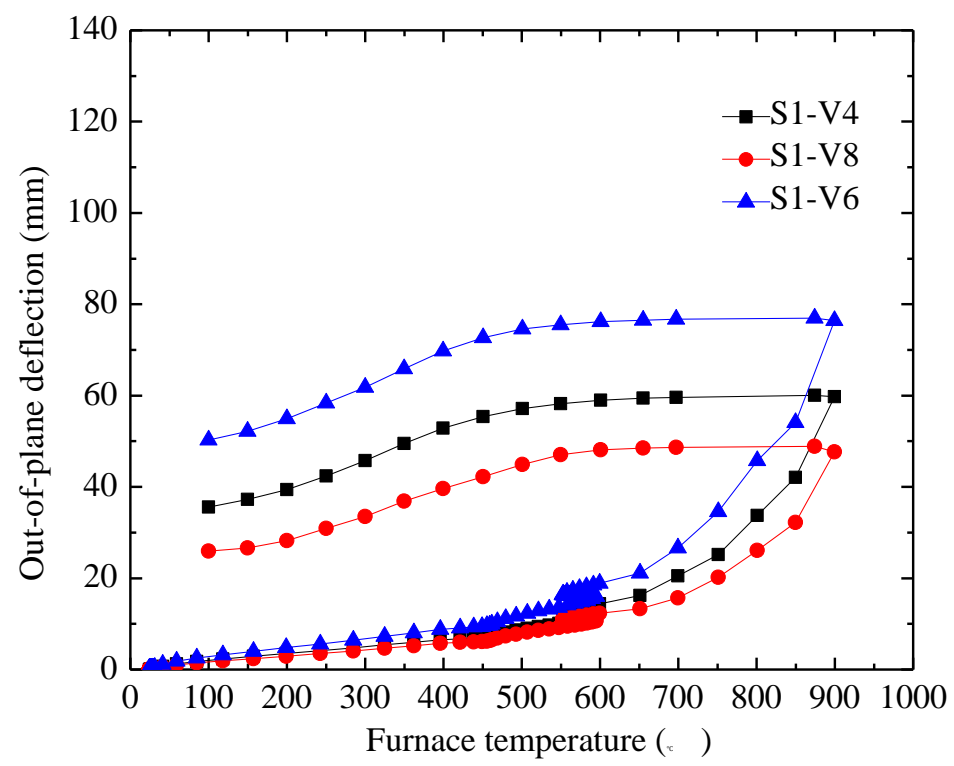

(a) Slab S1

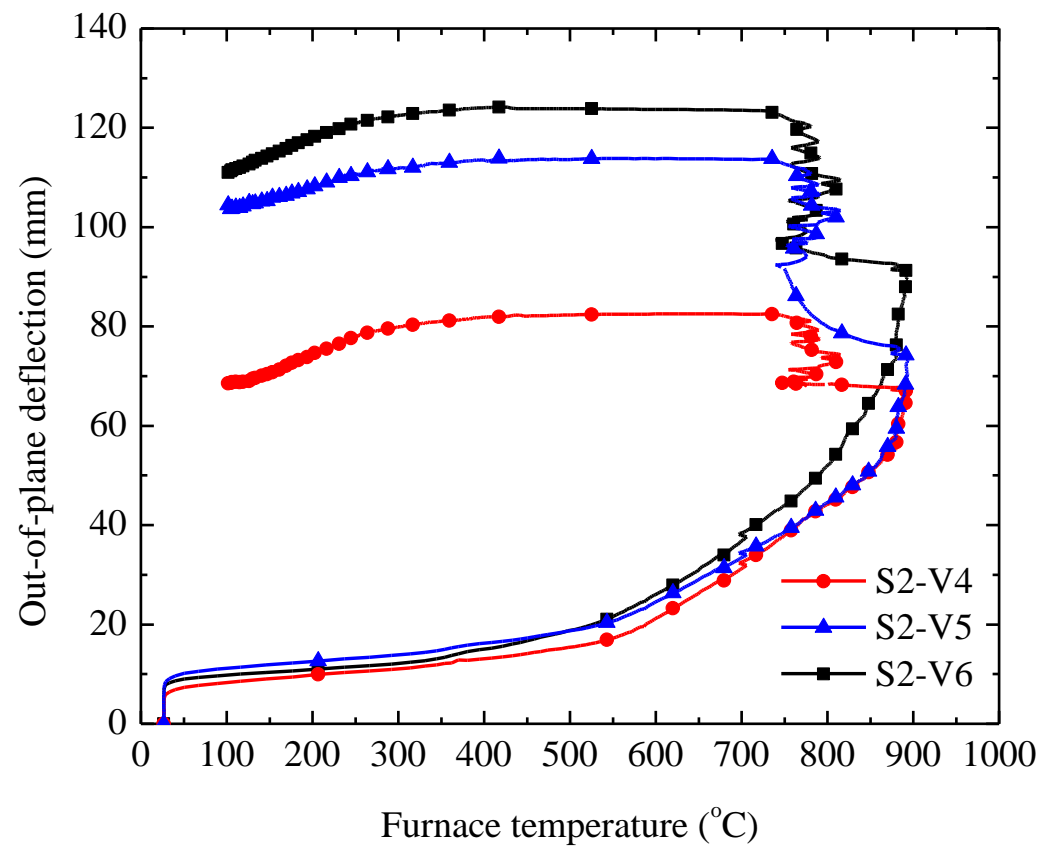

(b) Slab S2 


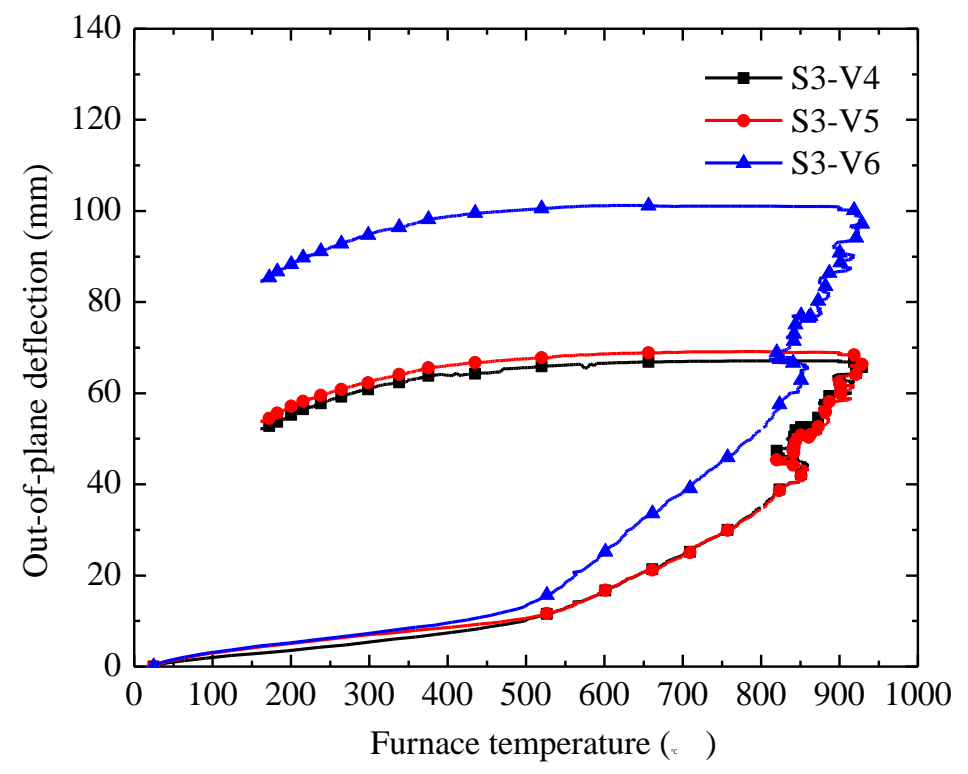

(c) Slab S3

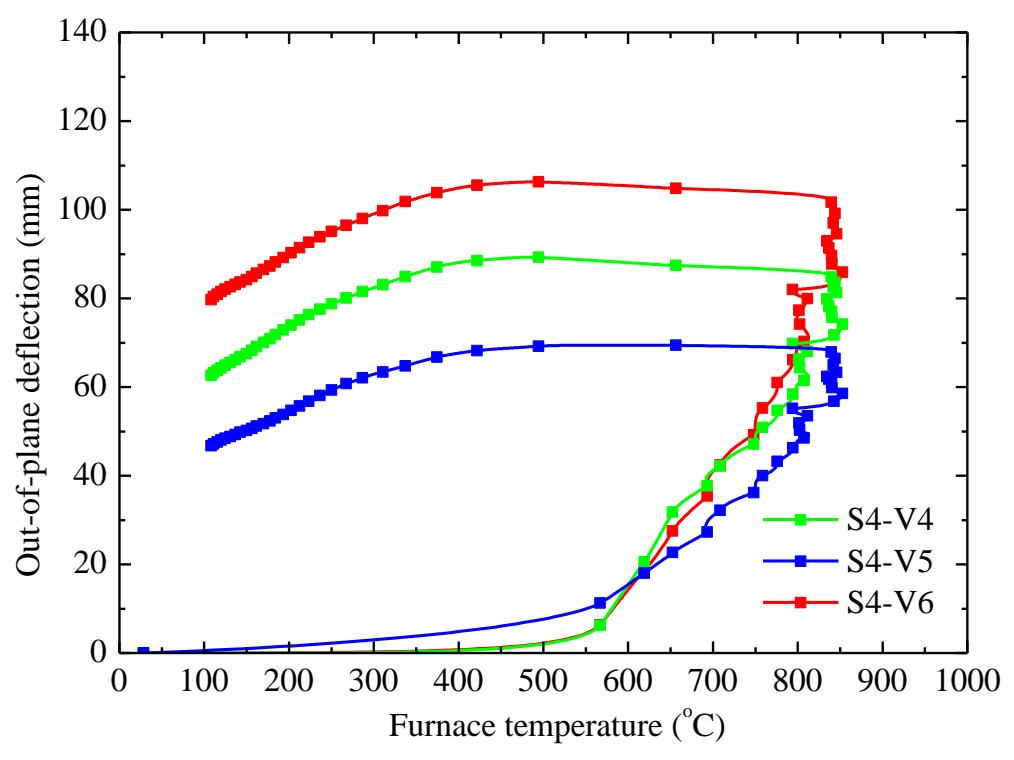

(d) Slab S4

Fig.9 Out-of-plane deflections-furnace temperature curves of the slabs: (a) Slab S1, (b) Slab S2, (c) Slab S3 and (d) Slab S4. 


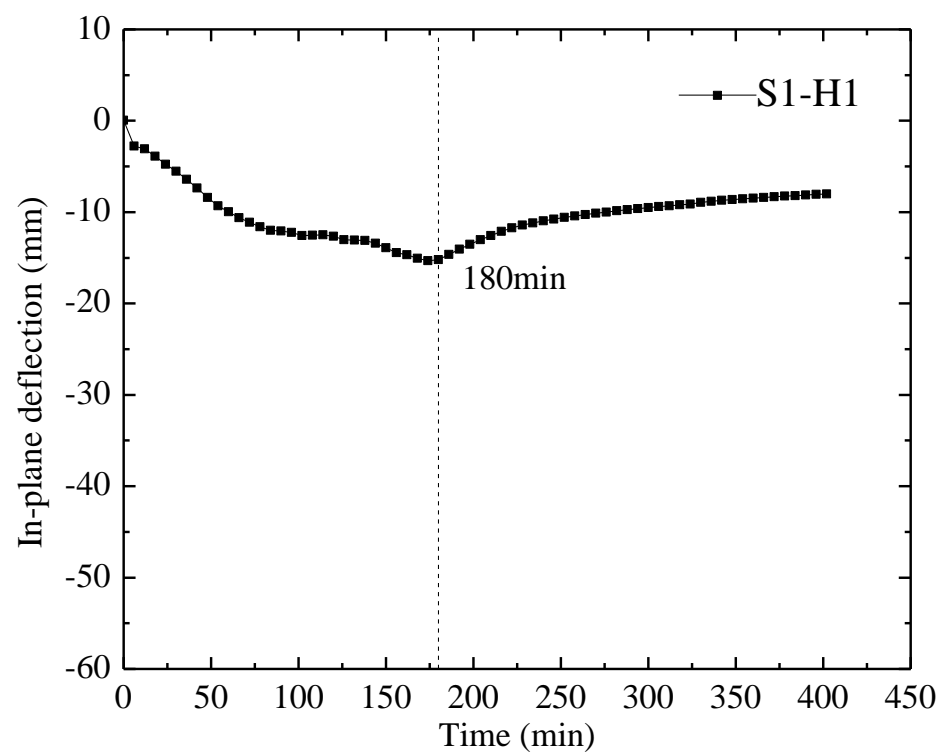

(a) Slab S1

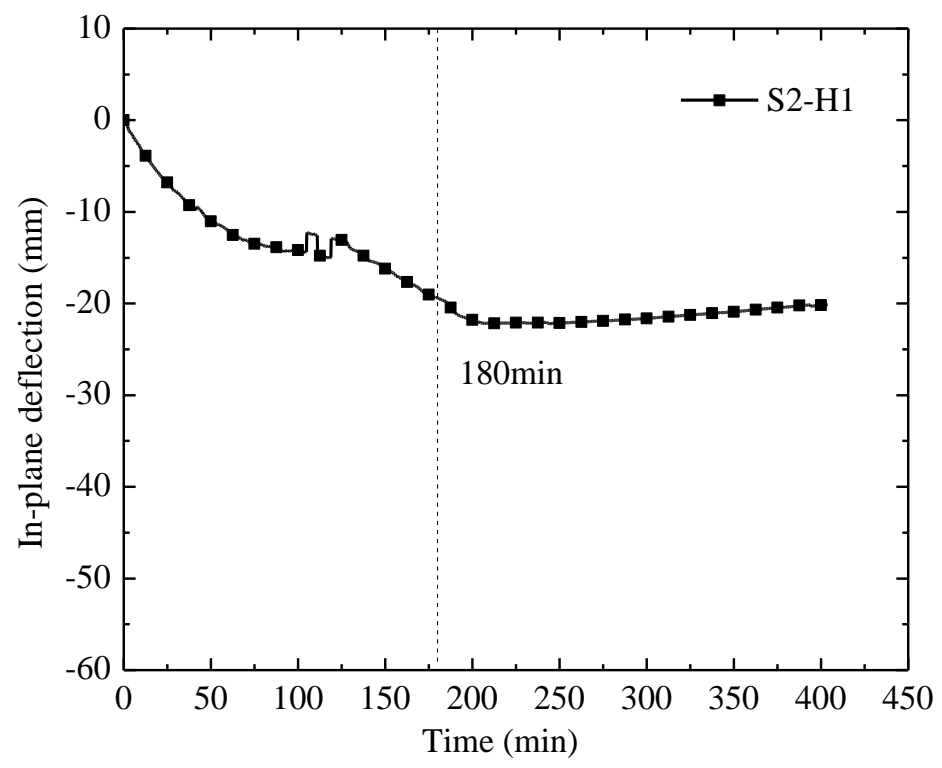

(c) Slab S2 


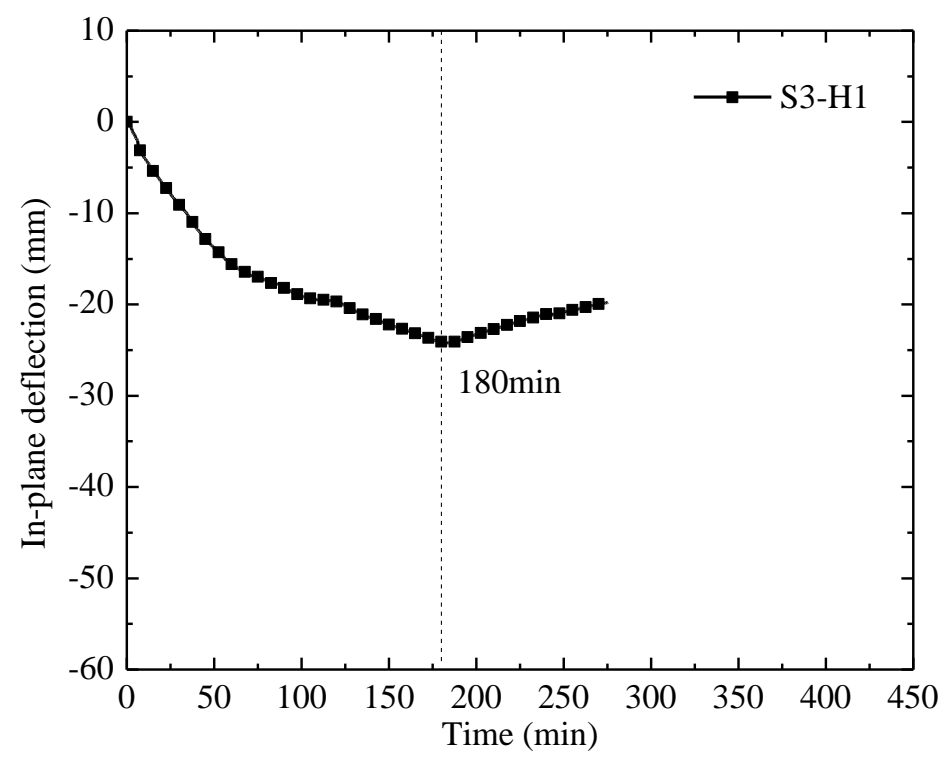

(c) Slab S3

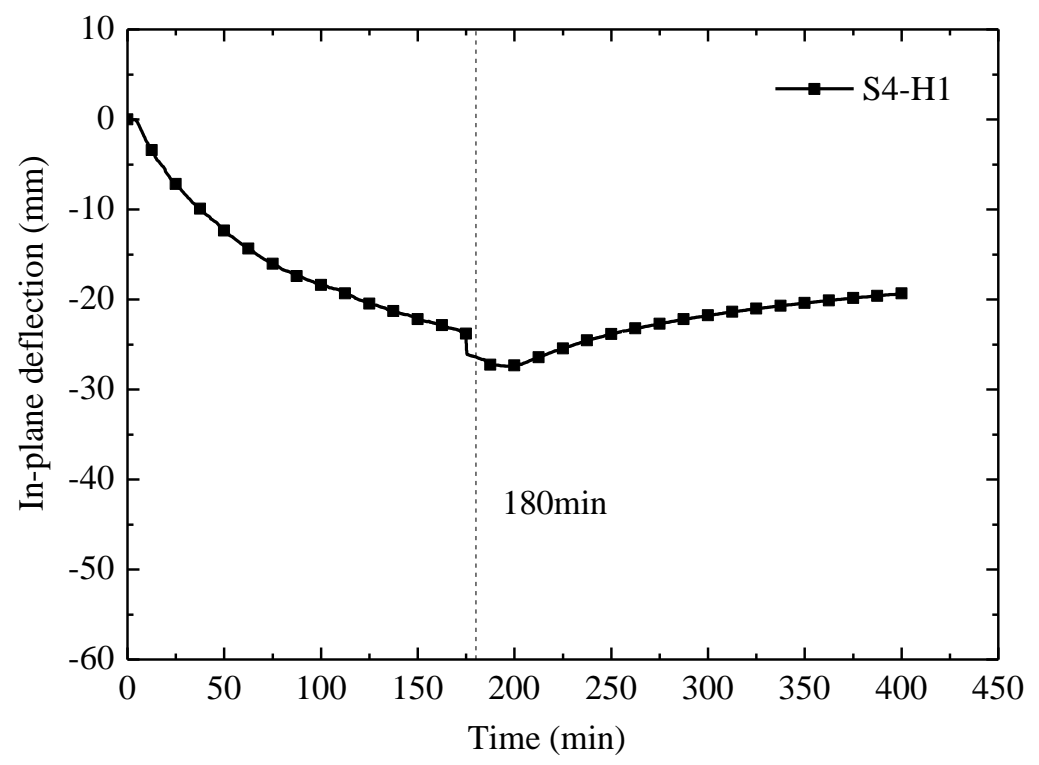

(d) Slab S4

Fig.10 Horizontal deflections of the slabs: (a) Slab S1, (b) Slab S2, (c) Slab S3 and (d) Slab S4. 


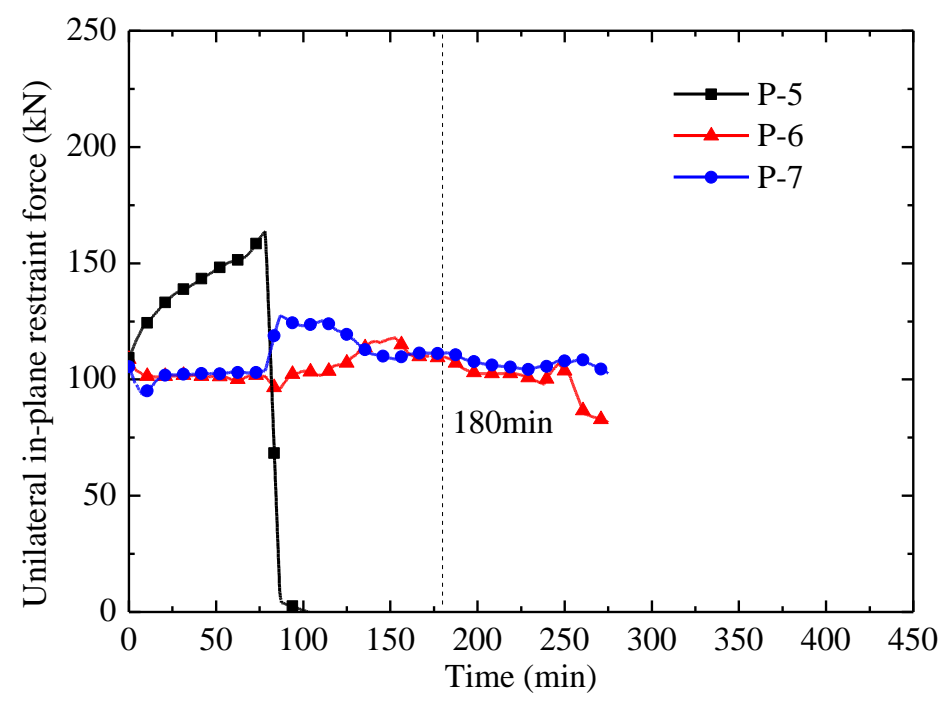

(a) Slab S3

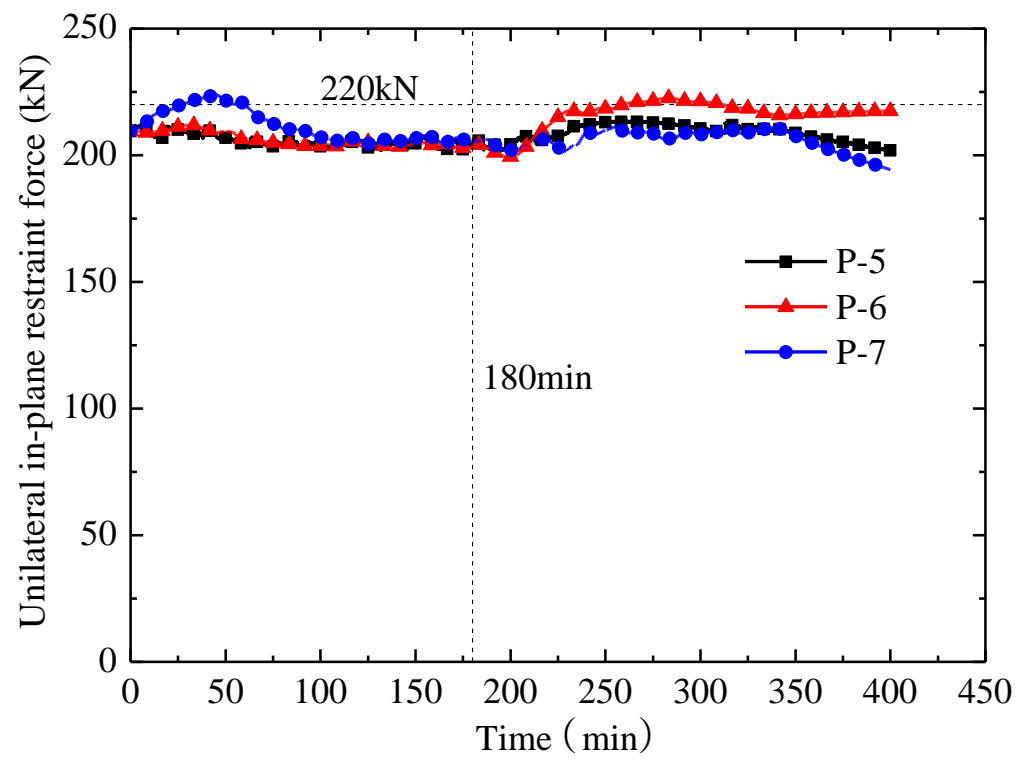

(b) Slab S4

Fig. 11 Measured uni-axial in-plane restraint forces in the slabs: (a) Slab S3 and (b) Slab S4. 


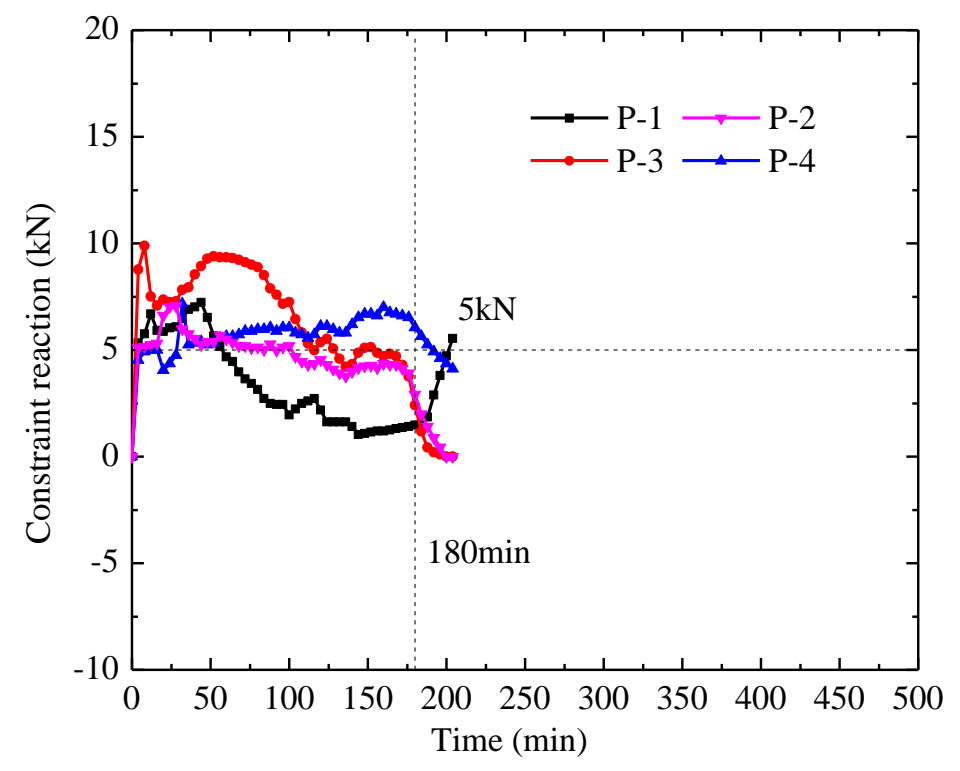

(a) Slab S1

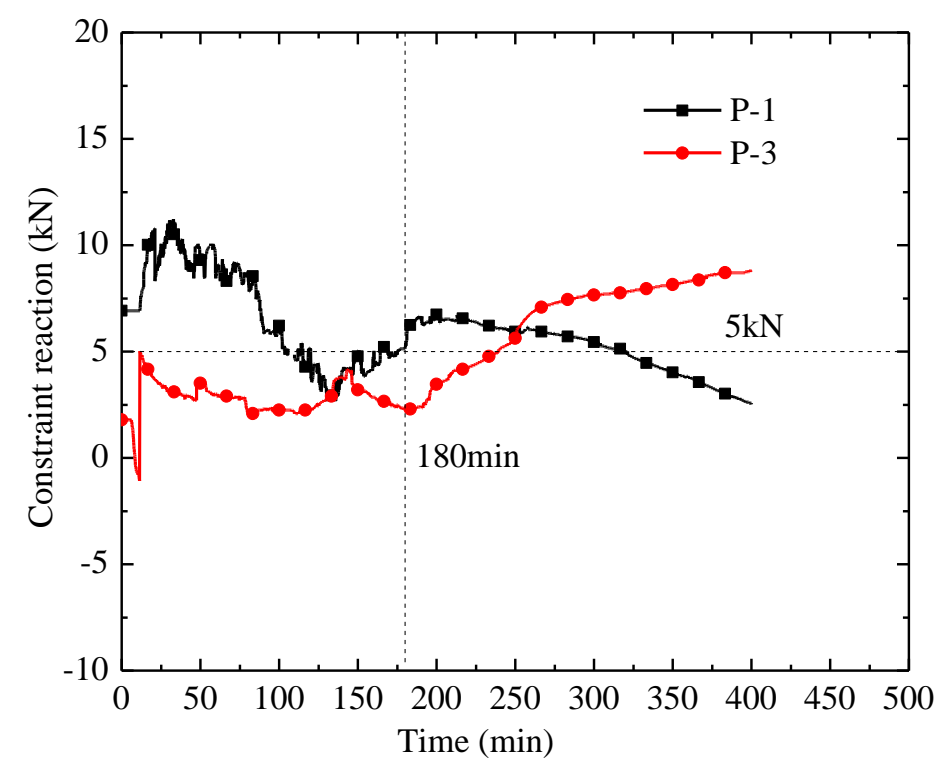

(b) Slab S2 


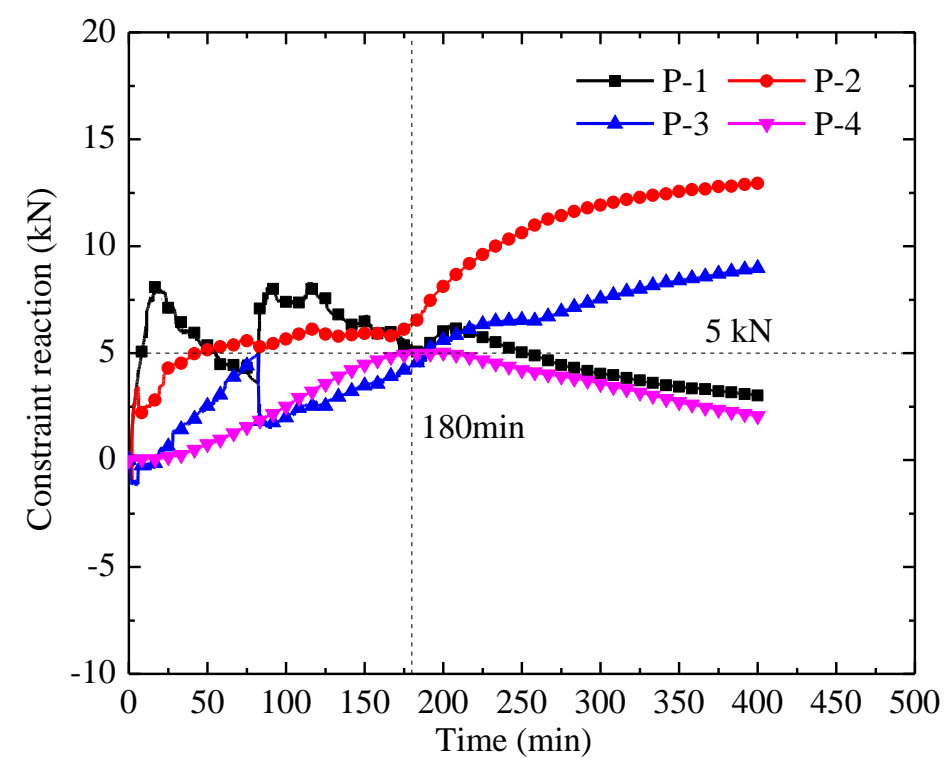

(c) Slab S3

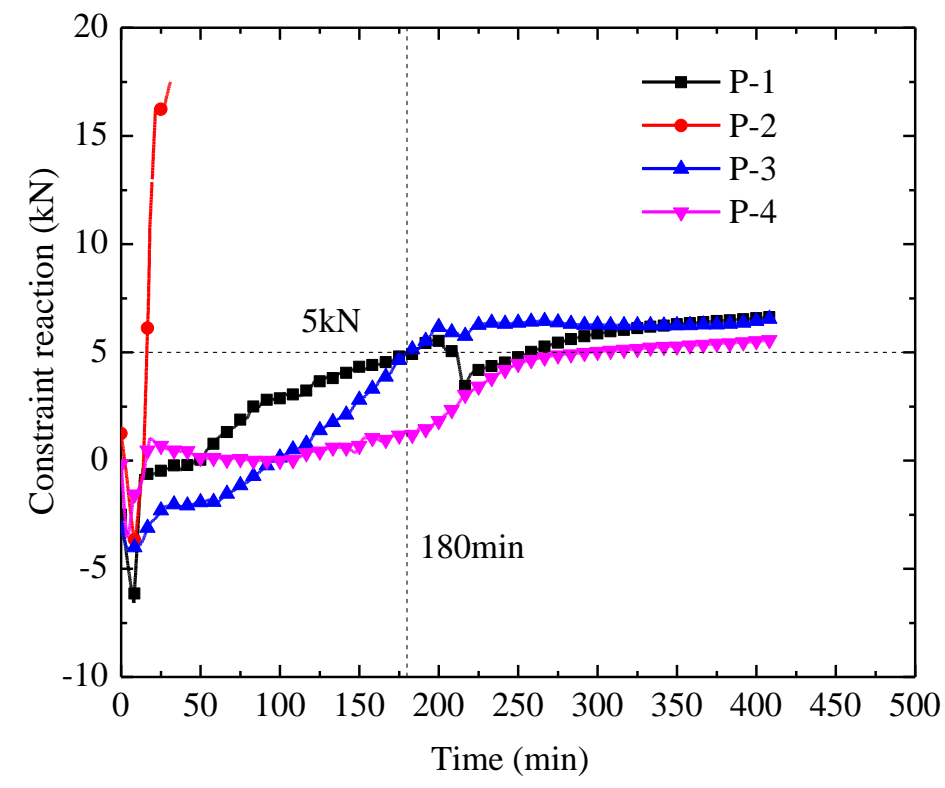

(d) Slab S4

Fig.12 Restrained forces at the corners of the slabs: (a) Slab S1, (b) Slab S2, (c) Slab S3 and (d) Slab S4. 


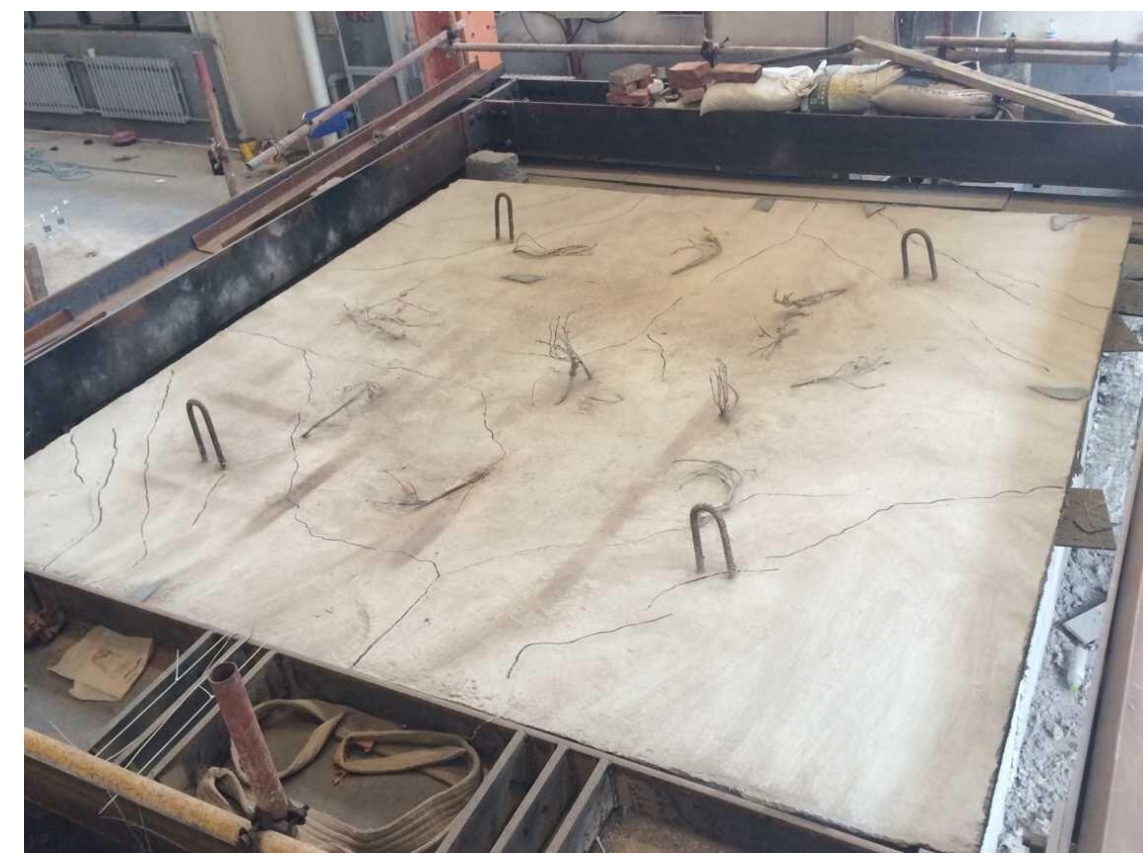

(a) Crack patterns at the top surface

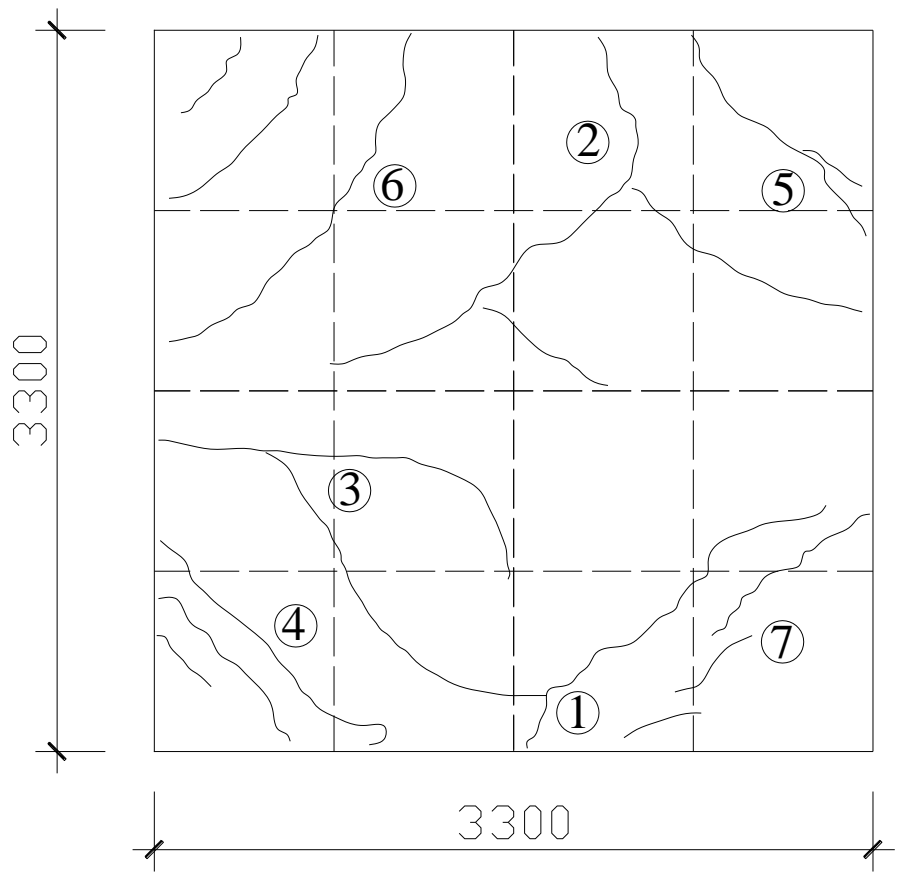

(b) Cracks' development during the test 


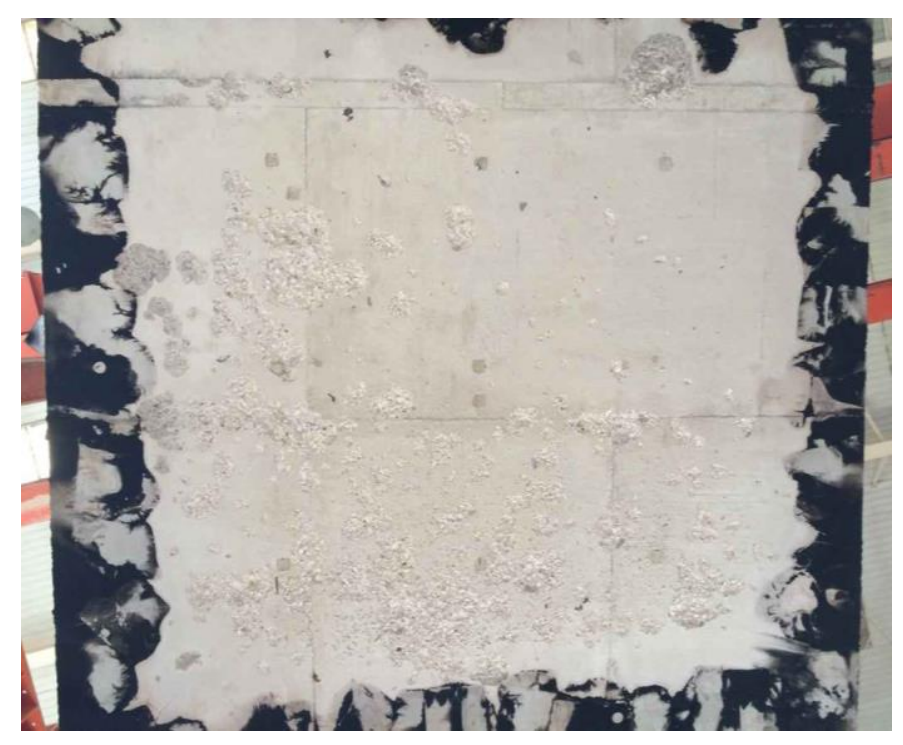

(c) Spalling at the bottom surface

Fig. 13 Failure models of the Slab S1: (a) Cracking pattern, (b) Cracks' development and (c) Spalling.

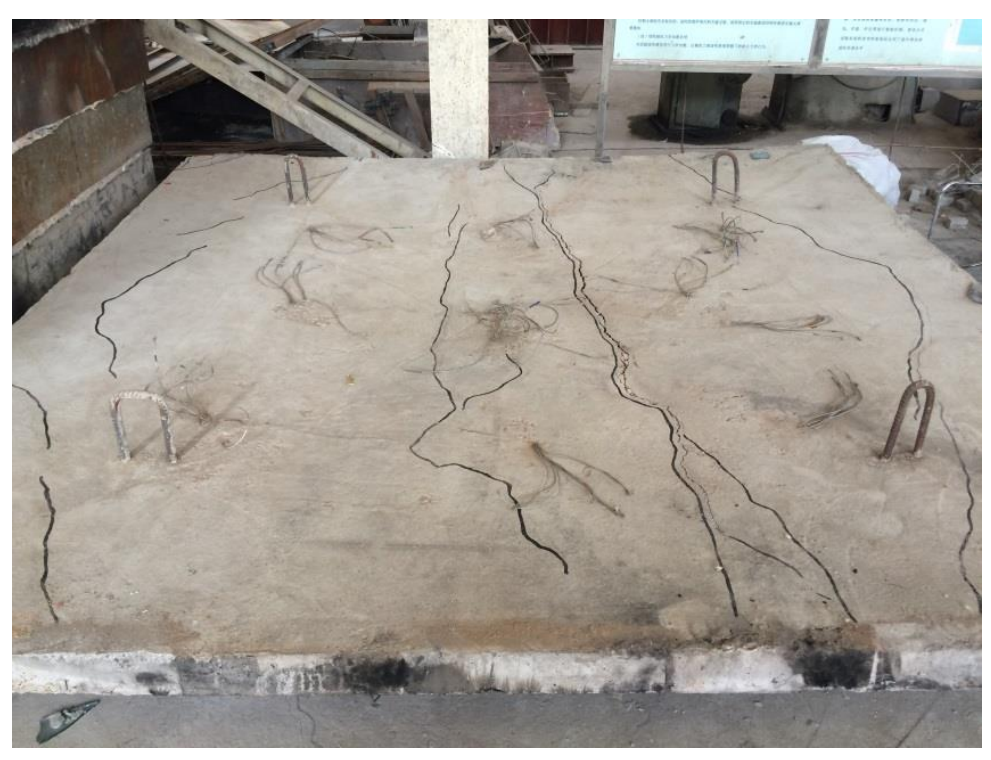

(a) Crack patterns at the top surface 


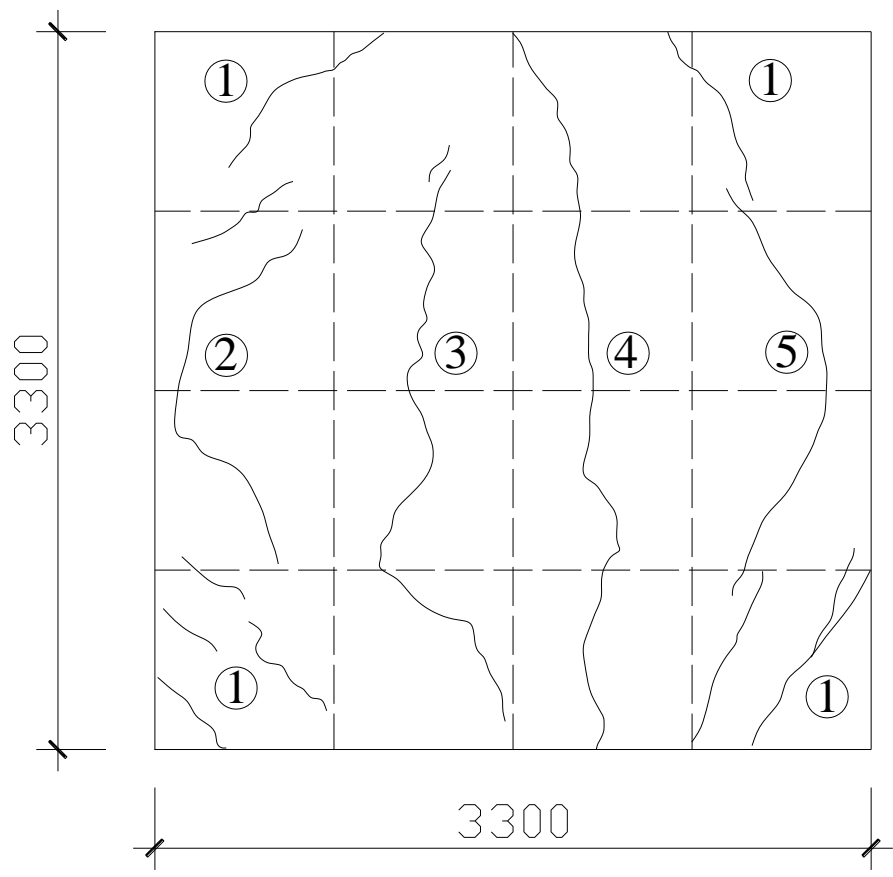

(b) Cracks' development during the test

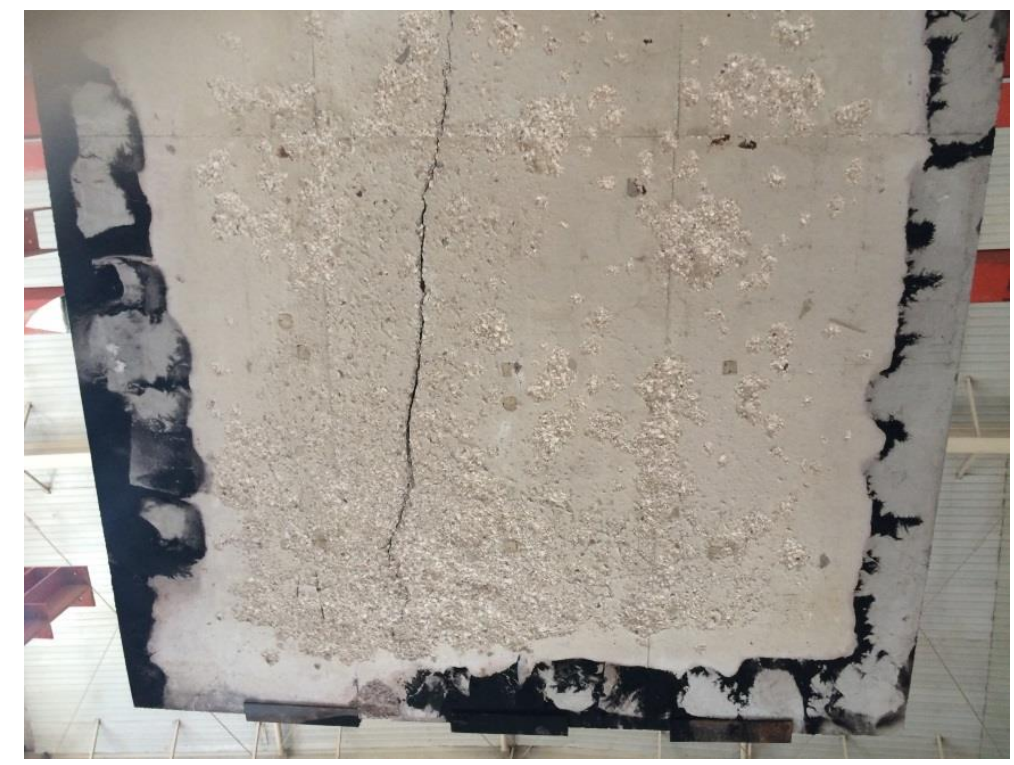

(c) Spalling at the bottom surface

Fig. 14 Failure models of the Slab S2: (a) Cracking pattern, (b) Cracks' development and (c) Spalling. 


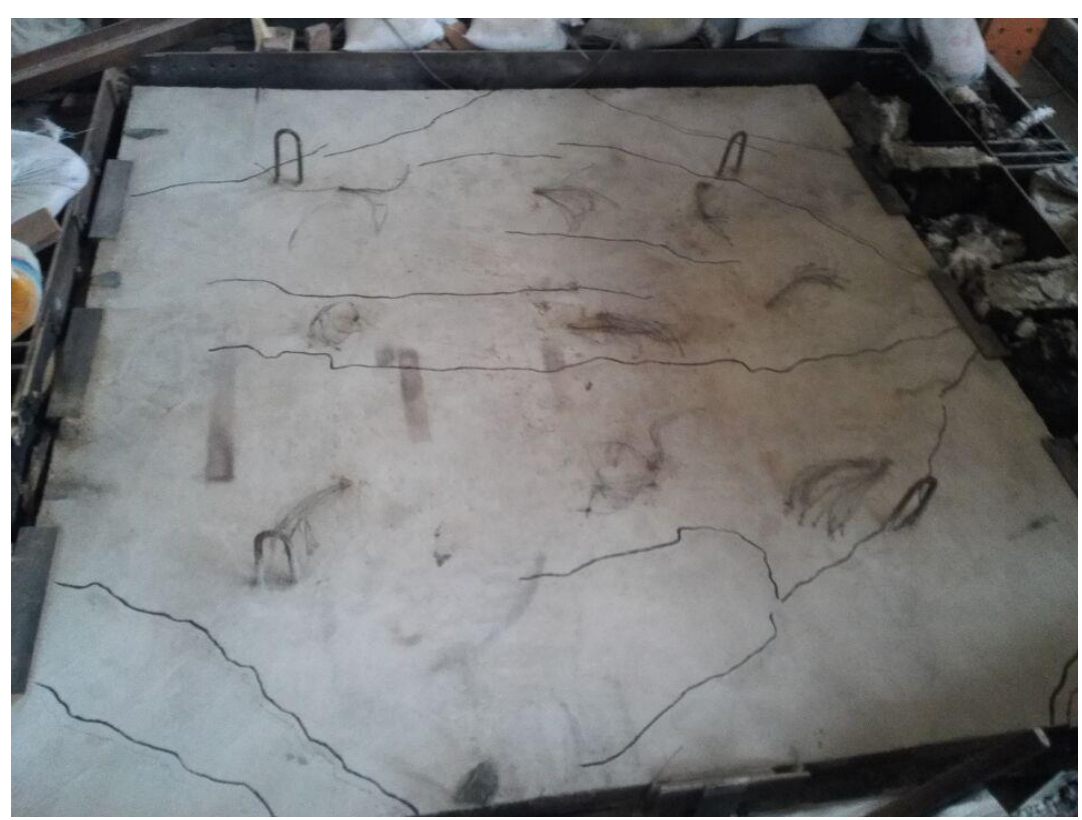

(a) Crack patterns at the top surface

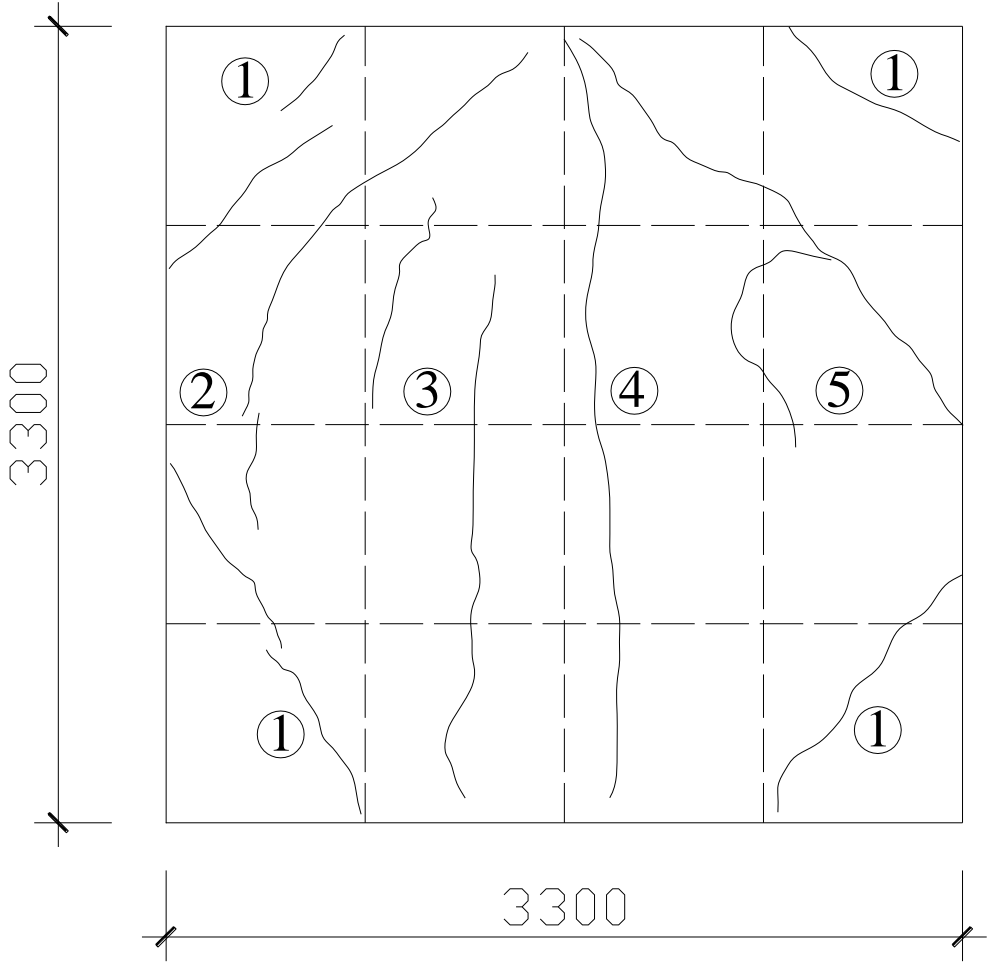

(b) Cracks' development during the test

Fig. 15 Failure models of the Slab S3: (a) Cracking pattern, (b) Cracks' development. 


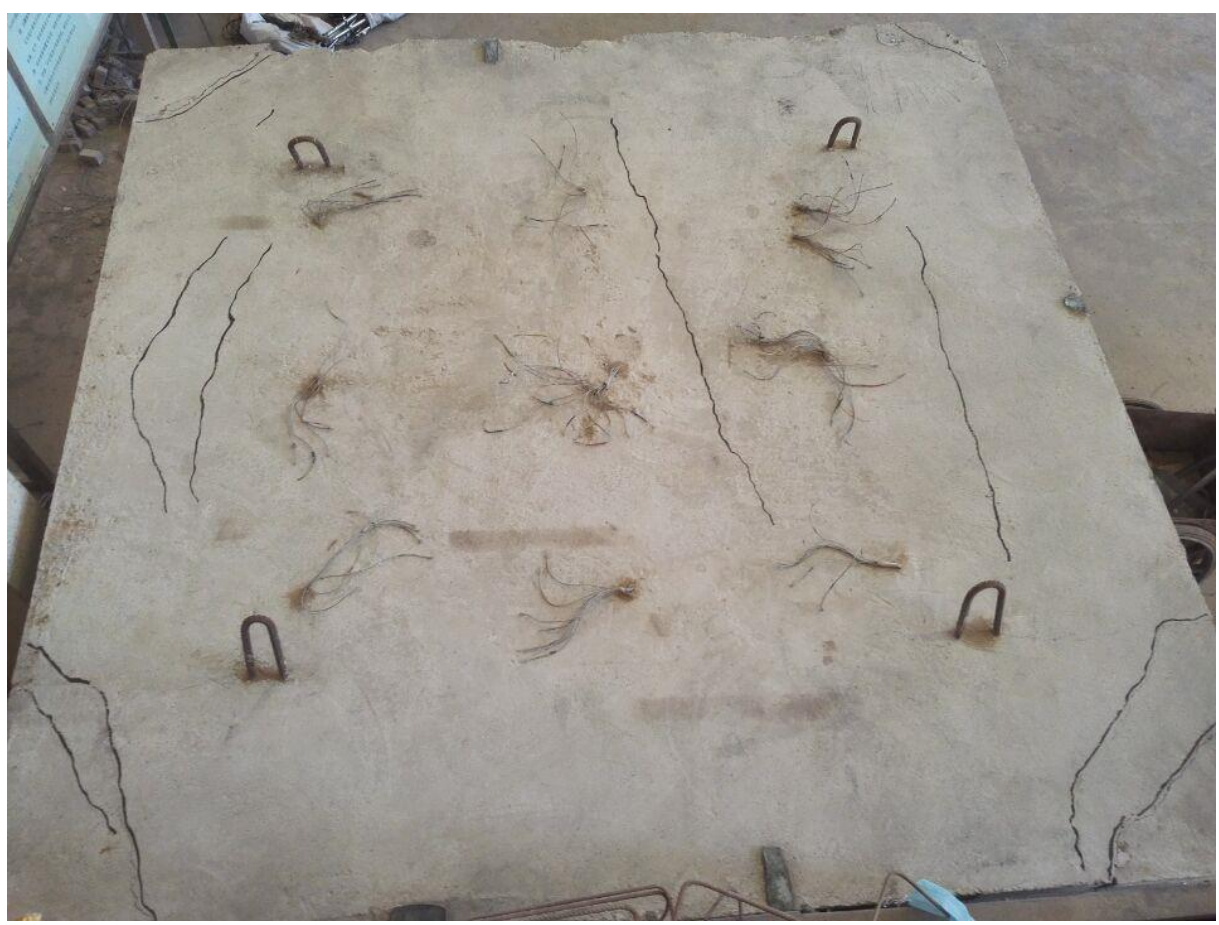

(a) Crack patterns at the top surface

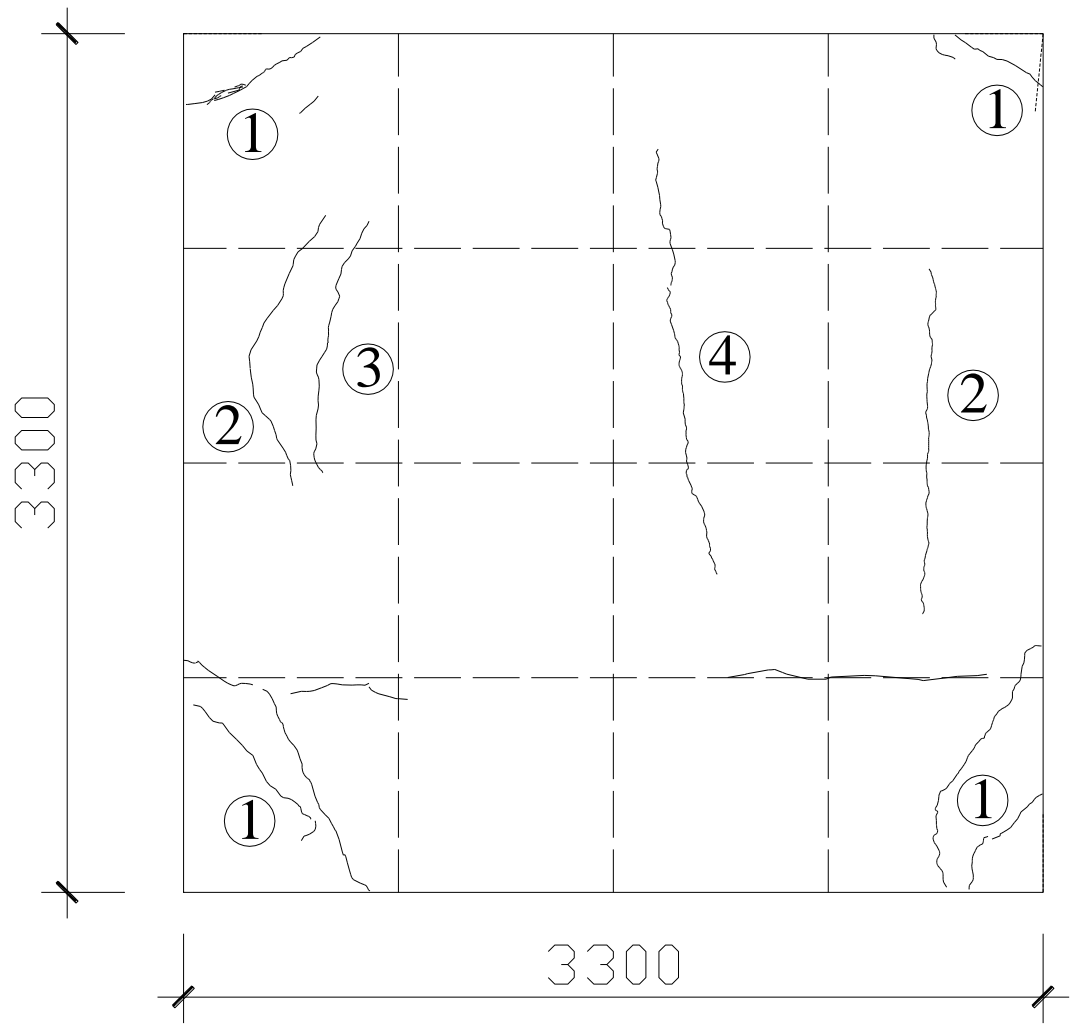

(b) Cracks' development during the test

Fig. 16 Failure models of the Slab S4: (a) Cracking pattern, (b) Cracks' development. 